\title{
SOME INVENTORY-RELATED ASYMMETRIES IN THE PATTERNING OF TONGUE ROOT HARMONY SYSTEMS ${ }^{*}$
}

\author{
Roderic F. Casali \\ Canada Institute of Linguistics, Trinity Western University and SIL International
}

\begin{abstract}
Earlier studies (e.g., Casali 2003, 2008) have presented evidence of significant differences in assimilatory tendencies in vowel systems that have an [ATR] contrast in high vowels ("/2IU/ systems") and those that have an [ATR] contrast only in non-high vowels ("/1IU/ systems"). Whereas assimilatory dominance of [+ATR] vowels is highly characteristic of the former, [-ATR] dominance is more typical of the latter. This paper investigates some further differences in the characteristic patterning of the two systems. I present evidence that /2IU/ and /1IU/ systems show essentially opposite markedness relations in respect to their non-low vowels, as diagnosed by distributional restrictions and positional

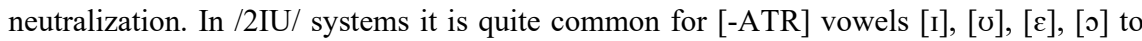
be more widely distributed than their [+ATR] counterparts $[\mathrm{i}],[\mathrm{u}],[\mathrm{e}],[\mathrm{o}]$, suggesting that the former are unmarked. In contrast, /1IU/ systems characteristically treat [-ATR] [I], [U], $[\varepsilon]$, [0] as marked relative to their [+ATR] counterparts. Low vowels do not show the same kind of striking reversal of markedness tendencies in the two systems that non-low vowels do. I argue, nevertheless, that some system-related differences can be observed in the patterning of low vowels as well.
\end{abstract}

Keywords: vowel harmony, advanced tongue root, typology, markedness, vowel length, vowel inventories

\section{Introduction}

Many African languages, especially in the Niger-Congo and Nilo-Saharan phyla, have vowel contrasts that have commonly been analyzed in terms of a feature [Advanced Tongue Root] ([ATR]). Quite a few such languages have a tongue root contrast in high vowels, leading to two sets of high vowels in phonemic contrast, $[+\mathrm{ATR}] / \mathrm{i} /, / \mathrm{u} /$ and $[-\mathrm{ATR}] / \mathrm{I} /, / \mathrm{\gamma} /$. Among the robustlyattested vowel inventories that display such a contrast are the ten-vowel system featured in (1a), found in languages like Akposso (Anderson 1999), a nine-vowel system in (1b), found in languages like Akan (Casali 2012, Clements 1981, Dolphyne 1988), and a seven-vowel system in (1c), found in languages like Kinande (Archangeli \& Pulleyblank 2002, Mutaka 1995). While the ten-vowel system in (1a) has a full complement of five [+ATR] (/i u e o a/) and five [-ATR] vowels $(/ \mathrm{I} \cup \in \rho \mathrm{a} /$ /), the nine-vowel inventory in (1b) is missing a low [+ATR] vowel /a /. The

* Substantial portions of the material in this paper appear in an unpublished paper, Casali (2014), available in the Rutgers Optimality Archive (http://roa.rutgers.edu), an earlier version of which was presented at a meeting of the Vancouver Phonology Group on October 15, 2013. I would like to thank participants in that meeting for helpful comments and discussion of the issues presented here. I would also like to thank John Alderete, Steve Parker, Keith Snider and the anonymous reviewers for this journal for their helpful comments. Any faults which remain are my own responsibility. 
seven-vowel inventory in (1c) is also missing such a vowel and, in addition, is missing mid [+ATR] vowel phonemes /e/, /o/. ${ }^{1}$

(1) Some well-attested tongue root harmony systems

a. $10 \mathrm{~V}$ inventory (e.g., Akposso)

$\begin{array}{llll}/ \mathrm{i} / & & / \mathrm{u} / & {[+\mathrm{ATR}]} \\ / \mathrm{I} / & & / \mathrm{J} / & {[-\mathrm{ATR}]} \\ / \mathrm{e} / & & / \mathrm{o} / & {[+\mathrm{ATR}]} \\ / \varepsilon / & & / \mathrm{o} / & {[-\mathrm{ATR}]} \\ & / \mathrm{a} /{ }^{2} & & {[+ \text { ATR }]} \\ & / \mathrm{a} / & & {[- \text { ATR }]}\end{array}$

c. $7 \mathrm{~V}$ inventory (e.g., Kinande)

$\begin{array}{llll}/ \mathrm{i} / & / \mathrm{u} / & {[+\mathrm{ATR}]} \\ / \mathrm{I} / & & / \mathrm{J} / & {[-\mathrm{ATR}]} \\ / \varepsilon / & & / \mathrm{J} / & {[-\mathrm{ATR}]} \\ & / \mathrm{a} / & & {[-\mathrm{ATR}]}\end{array}$

b. 9V inventory (e.g., Akan)

\begin{tabular}{|c|c|c|}
\hline /i/ & $/ \mathrm{u} /$ & [+ATR $]$ \\
\hline /I/ & $/ \mho /$ & [-ATR] \\
\hline /e/ & /o/ & [+ATR] \\
\hline $\mid \varepsilon /$ & $/ 0 /$ & [-ATR] \\
\hline & & [-ATR] \\
\hline
\end{tabular}

In keeping with the fact that they contain two sets of high vowels that contrast for tongue root position, such inventories are referred to in Casali (2008) as /2IU/ systems, and this terminology will be adopted in this paper as well.

It is also common to find vowel systems that lack an [ATR] contrast in high vowels but have such a contrast in mid vowels. The most common inventory of this type by far is the seven-vowel system in (2) which occurs in languages such as Yoruba (Archangeli \& Pulleyblank 1989, 1994).

\begin{tabular}{|c|c|}
\hline [+ATR $]$ & $/ \mathrm{i} /$ \\
\hline [+ATR $]$ & /e/ \\
\hline [-ATR] & $/ \varepsilon /$ \\
\hline [-ATR] & \\
\hline
\end{tabular}

Following Casali (2008), a vowel system that has a tongue root contrast only in non-high vowels will be referred to as a /1IU/ system.

Although the seven-vowel system in (2) is the most commonly occurring /1IU/ system, /1IU/ systems with an additional central vowel, perhaps most typically a mid central [+ATR] vowel /a/ (see Section 5 below for extended discussion) are also well attested. Examples of such eight-vowel

1 Though missing as phonemes in the seven-vowel system in (1c), the mid [+ATR] vowels [e], [o] often occur as allophones in languages with this system (Casali 2003).

2 The symbol [a] is used throughout this paper to represent a low [+ATR] vowel. Although the sevenvowel system in (2) is the most commonly occurring /1IU/ system, /1IU/ systems with an additional central vowel, perhaps most typically a mid central [+ATR] vowel /a/ are also well attested, e.g., DiolaFogny (Sapir 1965), Akoose (Hedinger \& Hedinger 1977) and Wolof (Ka 1987, Pulleyblank 1996); see Section 6 below for discussion. 
systems include Akoose (Hedinger \& Hedinger 1977), Likpe (Lomotey 2009, Ring 2003) and Wolof (Ka 1987, Pulleyblank 1996). ${ }^{3}$ Similarly, there are also languages, e.g., Zande (R. Boyd 1997), which supplement a basic seven-vowel inventory of the type in (1c) with an additional central vowel that functions as the [+ATR] counterpart of /a/, yielding an overall eight-vowel system.

Two terminological points are worth clarifying here. First, I assume, following Casali (2008), that the classification of a language's inventory type (/1IU/ or /2IU/) is based on the contrastive vowel inventory of a language and not its surface phonetic inventory. This means that to qualify as a /2IU/ system, a language must have two sets of phonemic high vowels. Thus, a language like Ijesa Yoruba (Oyelaran 1973, Orie 2003), which has a phonemic seven-vowel inventory of the type in (2) but a surface nine-vowel [i I e $\varepsilon$ a $\rho$ o $v \mathrm{u}$ ] inventory, due to existence of surface high [-ATR] vowels [I], [U] which occur as conditioned allophonic variants of $/ \mathrm{i} /, / \mathrm{u} /$ preceding [-ATR] vowels $[\varepsilon]$, [a], [0], is considered to be a /1IU/ rather than a /2IU/ system. Second, the terms /1IU/ and /2IU/ are meant to apply only to inventories in which [ATR] is contrastive. There are, of course, a great many African languages with five-vowel systems (/i $\varepsilon$ a $\rho \mathrm{u} / \mathrm{or} / \mathrm{i}$ e a o $\mathrm{u} /$ ) in which a feature [ATR] is not employed contrastively at all. Such languages do not qualify as either /1IU/ or $/ 2 \mathrm{IU} / \mathrm{systems}$ and will not form part of the discussion.

Both /1IU/ and /2IU/ systems commonly manifest some form(s) of vowel harmony or assimilation based on the feature [ATR]. It would be entirely reasonable to expect to find similar assimilatory patterns in the two systems. For example, it has long been known that ATR harmony languages in which [+ATR] vowels are dominant, i.e., in which [-ATR] vowels assimilate to [+ATR] vowels but not conversely, are quite strongly attested. From this we might fairly suppose that assimilatory spreading of $[+$ ATR $]$ is a highly natural process. Since both system types contain both [+ATR] vowels that might be expected to serve as triggers of [+ATR] spreading and [-ATR] vowels that could serve as targets of such spreading, it would be entirely natural to assume that such spreading should be common enough in both types of systems.

Surprisingly, however, there is good evidence of some major differences in the characteristic assimilatory behaviors of the two systems. While /2IU/ systems very commonly manifest various forms of [+ATR] dominance (and much more rarely show evidence of [-ATR] dominance), clear indicators of [+ATR] dominance are much less commonly found in /1IU/ systems, in which [ATR] vowels are more typically dominant (Casali 2008, Clements 2000). The suggestion that [+ATR] vowels are characteristically dominant in /2IU/ systems while [-ATR] vowels are dominant in /1IU/ systems can be found in work dating back to the early 1990s (e.g., Casali 1993, 1996, 1998, Goad 1993, Steriade 1995, Akinlabi 1997), but received comparatively little attention during the 1990s. More recently, however, a cross-linguistic study of 110 Niger-Congo and NiloSaharan languages reported in Casali (2003) has provided considerably stronger support for the claim. Although the existence of some apparent exceptions (discussed below) suggests that aspects

3 More rarely, both /1IU/ and /2IU/ systems with two or more non-low central (or, in a few cases, front rounded) vowels occur as well. For example, Attie (a Kwa language described in Kutsch Lojenga \& Hood 1982) has a nine-vowel /1IU/ system in which the seven vowels in (2) are supplemented by two phonemic non-low central vowels /a/ and /i/. The Kru language Bete (Marchese 1983, Werle \& Dagou 1976) has two non-low central [+ATR] vowels and two non-low central [-ATR] vowels in addition to the nine vowels in (1b). The Kwa language Abron (Ravenhill 1982) has the nine-vowels in (1b) plus a high front rounded vowel $/ y /$ that patterns as a [+ATR] vowel. Other cases exist as well. 
of the generalization that [+ATR] is dominant in /2IU/ systems and [-ATR] in /1IU/ systems may not be entirely universal, the generalization is a strong one.

The major aim of this paper is to build on the conclusions of Casali (2003) by providing additional findings that bear on the existence of system-related differences in phonological patterning. First, I look at a further potential diagnostic of assimilatory dominance, involving root internal co-occurrence possibilities for high [+ATR] and mid [-ATR] vowels, which was not considered in Casali (2003). I propose that /1IU/ systems far more typically tolerate co-occurrence of [i], [u] with $[\varepsilon],[0]$ than $/ 2 \mathrm{IU} /$ systems, and that such a difference is convergent with the conclusion argued for in earlier work that [-ATR], and not [+ATR], is regularly dominant in /1IU/ systems.

Second, we will consider positional neutralization patterns, i.e., cases in which tongue root contrasts found in some positions (e.g., roots, or lexical / content morphemes) are neutralized in other, less prominent positions (e.g., affixes, or function / grammatical morphemes). Such patterns are generally assumed to be potentially indicative of markedness relations, the standard assumption being that positional neutralization is to the unmarked member of an opposition (Beckman 1997, de Lacy 2006, Hume 2011, Kiparsky 2006: 218, Rice 2007, Steriade 1995). I present evidence that $/ 2 \mathrm{IU} /$ and $/ 1 \mathrm{IU} /$ systems show essentially opposite positional neutralization tendencies involving non-low vowels. Overwhelmingly, /2IU/ systems positionally neutralize tongue root contrasts to [-ATR] at all tongue heights, effectively treating [-ATR] as the unmarked value. While the finding that [ATR] contrasts in non-high (and, especially, low) vowels should be neutralized positionally to [-ATR] is unsurprising under widely held views about the markedness of particular combinations of height and tongue root features (see, for example, Archangeli \& Pulleyblank 1994, Calabrese 1995), the finding that tongue root contrasts in high vowels should also be neutralized to [-ATR] is a much more surprising result. Such a conclusion goes squarely against the very widespread assumption that [-ATR] is universally marked in high vowels, due to a gestural antagonism between tongue body raising and tongue root retraction (Archangeli \& Pulleyblank 1994, 2002, Bakovic 2000, Calabrese 1995, Leitch 1996, Wayment 2009, among others).

In contrast, /1IU/ systems clearly treat [+ATR] as the unmarked value in high vowels (inasmuch as high [-ATR] vowels are entirely absent in the vast majority of /1IU/ systems), as much theoretical work on the topic would lead one to expect. More surprisingly, however, they also show a strong tendency to positionally neutralize mid vowel contrasts to $[+\mathrm{ATR}][\mathrm{e}]$, [o] and not (as in /2IU/ systems) [-ATR] [ع], [o].

Finally, we will look at some differences involving the patterning of low vowels. Three specific types of differences will be discussed. First, whereas genuinely low [+ATR] vowels are clearly attested (though uncommon) in /2IU/ systems, the existence of such cases in /1IU/ systems is at this point much less clear. While it is certainly possible to find /1IU/ systems with a non-high central vowel, often transcribed /o/, that functions harmonically as the [+ATR] counterpart of /a/, it is not at all easy to find /1IU/ languages in which such a vowel is unambiguously low. Whether this absence simply reflects a descriptive gap that will eventually be filled by further research remains to be seen, but it is an issue that at least merits some discussion. Second, to the extent that cases of arguably (if not unambiguously) low, or at least non-high, [+ATR] central vowels exist in /1IU/ systems, such vowels show surprisingly little clear evidence at present of patterning (as they clearly do in /2IU/ systems) as marked sounds. Finally, in a number of seven-vowel /i e $\varepsilon$ a $っ$ o u/ /1IU/ languages in which mid vowels harmonize for [ATR], the low vowel /a/, though 
phonetically retracted, fails to condition [-ATR] allomorphs of harmonizing affixes with mid vowels, taking allomorphs with [+ATR] mid vowels [e] or [o] instead. In some such languages (e.g., those of Bantu Zone C; Leitch 1996), [a] is able to co-occur root internally with [+ATR] [e], [o] but not with [-ATR [ $\varepsilon]$, [o]. No patterns of these types have ever been reported in any /2IU/ languages, as far as I am aware. Rather, in all known /2IU/ systems, the vowel [a] both freely combines with non-low [-ATR] vowels and, as a root vowel, consistently triggers [-ATR] allomorphs of harmonizing affixes.

The typological generalizations presented in this paper have implications both for phonological theory, in that there is a need to understand why the two inventories should pattern differently in the ways that they do, and for descriptive practice, in that they suggest research topics and questions that might profitably be investigated in the course of descriptive fieldwork on a tongue root harmony language. Implications are briefly discussed in the final section of the paper.

The remainder of this paper is organized as follows. In Section 2, I address an important preliminary issue, involving the question of whether it is in fact possible to reliably distinguish two different types of seven-vowel systems (one with a tongue root contrast in high vowels, as in (1c), and one with a tongue root contrast in mid vowels, as in (2)). The issue is worth addressing inasmuch as questions have sometimes been raised as to whether the two systems can be distinguished in a non-arbitrary way (Clements 1991, Hyman 1999, Parkinson 1996). Section 3 briefly reviews the major findings of Casali (2003), which reveal that [+ATR] is characteristically dominant in /2IU/ systems, while [-ATR] is more typically dominant in /1IU/ systems. Different tendencies involving the co-occurrence of high [+ATR] and mid [-ATR] vowels are treated in Section 4, while differences involving positional neutralization patterns in non-low vowels are taken up in Section 5. Section 6 discusses some inventory-related differences in the behavior of low vowels. Finally, Section 7 briefly summarizes the paper's findings and their potential implications for phonological theory and descriptive research practice.

\section{Issues in the categorization of seven-vowel systems}

An important question that potentially arises in connection with the vowel inventories described in (1) and (2) above is whether it is even possible to reliably distinguish the two different sevenvowel inventories in (1c) and (2). High [-ATR] and mid [+ATR] vowels are known to be auditorily very similar to each other (Casali 2002a, 2008). In many such languages, the two sets are not easily distinguishable by means of their $F_{1}$ values, which often significantly overlap (Casali 2008, Starwalt 2008). Given that the two sets are often so similar impressionistically and difficult to distinguish by the most straightforward acoustic measurements (formant frequencies), how is it possible to establish, in some kind of consistent and non-arbitrary way, whether the second highest ("Height 2") vowels in a seven-vowel system are /I/, / / (in which case the system will be of the type in (1c)) or /e/,/o/ (in which case the system will be of the type in (2))? A maximally skeptical answer to this question might suppose that there is no distinction between the two systems, and that the decision to analyze a given seven-vowel system as one type or the other on phonetic grounds is purely arbitrary. That is, one might claim that since the only auditory difference between the two sets in languages in which both occur is one of auditory height (correlated with a vowel's first formant frequency), and since impressionistic vowel height is relative, with no absolute thresholds between categories, the choice of whether Height 2 vowels in a seven-vowel system are high vowels $/ \mathrm{I} /, / \mho /$ or mid vowels /e/, /o/ is indeterminate. The problem 
is discussed by Hyman (1999), who notes the existence of some individual seven-vowel languages which have been described by some researchers as of the type in (1c) and by others as of the type in (2).

The question is clearly an important one, which has arguably received far less attention than it deserves. My own view on the matter (Casali 2003: 326-330) is that an analytical choice between the two inventories is not purely arbitrary, but that there are criteria which can decide the matter in principle and often in practice. This does not guarantee, however, that application of these criteria will always be straightforward in practice. There may well be particular seven-vowel languages whose classification into one or the other type proves difficult. (One possible case is considered in Section 5.1 below.)

While the relevant issues are complex enough that they cannot be treated in full depth here, I will briefly outline, in what follows, some reasons to suppose that the distinction is not purely arbitrary or a matter of transcriptional preference. It rather reflects a phonetically and phonologically meaningful distinction and that various criteria can be appealed to in principle and in practice to determine which of the two types is found in a given seven-vowel language (see Casali 2003 and Starwalt 2008).

First, it is appropriate to begin with the simple observation that the two systems, as transcribed in (1c) and (2), characterize different articulatory realities. In a language whose system is of the type in (1c), we should expect to find a difference in tongue root positon (or, more generally, pharyngeal cavity volume; Casali 2008: 506, Lindau 1979, Tiede 1996) accompanying the Height 1 and Height 2 vowels (with Height 2 vowels retracted relative to their Height 1 counterparts), while in a system of the type in (2), we should expect to find such a difference occurring with the Height 2 and Height 3 vowels (with the latter showing a more retracted tongue root position than the former).

Two ultrasound investigations of tongue root mechanisms in seven-vowel languages are of clear interest. An ultrasound study of Kinande by Gick et. al. (2006) clearly reveals that the Height 1 and Height 2 vowels differ in tongue root position, with the latter significantly retracted relative to the former, justifying the standard analysis of the language as a system of the type in (1c) (Archangeli \& Pulleyblank 2002, Mutaka 1995). (As discussed below, this analysis of Kinande is also clearly warranted by phonological patterns in the language as well.) A study of Yoruba by Allen et. al. (2013) shows a different result. In this language, it is the Height 2 and Height 3 vowels that show a clear difference in tongue root positon (with the position of the former being advanced relative to the latter), as might be expected under the usual analysis of this language as a seven-vowel /i e $\varepsilon$ a $ว$ o u/system (i.e., a system of the type in (2)) (Archangeli \& Pulleyblank 1994, Orie 2003, Pulleyblank 1996).

Of course, extremely few seven-vowel languages have so far been investigated using ultrasound technology (the studies of Kinande and Yoruba just referred to are the only such cases I am currently aware of). Nevertheless, these studies suggest that the two types in (1c) and (2) can, in principle, be distinguished on phonetic grounds, and that the difference does not reduce to a purely arbitrary difference in transcriptional preferences for Height 2 vowels. Moreover, it is significant, in my view, that the conclusions arrived at through these ultrasound investigations are fully convergent with those adopted in previous analyses of these two languages, which did not have the benefit of direct instrumental observation of articulatory mechanisms and relied instead on a combination of impressionistic phonetic transcriptions and observations of phonological 
patterning (about which more is said below). This convergence suggests that analyses of the former type are not to be discounted and not necessarily a matter of arbitrary analytical choices.

Second, it is also important to emphasize that the question of whether a seven-vowel language's Height 2 vowels are articulated with tongue root advancement or retraction is not a question that can be answered only by ultrasound (or some similar) technology. Differences in tongue root positon, and accompanying differences in pharyngeal cavity volume, are known to give rise to different secondary auditory cues, often discussed under the label "voice quality", which transcend differences in impressionistic "height" (correlated with a vowel's first formant frequency) (Casali 2008, Jacobson 1978, 1980, Kingston et al. 1997, Pike 1967, Starwalt 2008, Tucker 1975). Expansion of the pharyngeal cavity (produced chiefly by tongue root advancement, but facilitated in some languages by additional mechanisms such as larynx lowering) gives rise to an overall hollower or deeper quality, while pharyngeal cavity constriction in retracted-tongueroot vowels leads to a perceptual quality that has been described by terms such as "bright" or "creaky." While such voice quality differences have been more widely reported in East African (especially, Nilo-Saharan) languages, they have been reported in various West African languages as well, including Abua (Ward 1937 as cited in Stewart 1967), Ahanta (Berry 1955), Anum (Painter 1971), Akan (Dolphyne 1988), Degema (Fulop et. al. 1998), Nzema (Berry 1955), Nawuri (Casali 2002a) and various languages discussed in Starwalt (2008). In my view (see Casali 2008: 509-510 for some discussion), they are very likely much more widespread in West Africa than is readily evident in the literature to date.

Such auditory differences play an important role in distinguishing high [-ATR] from mid [+ATR] vowels perceptually in languages in which the two sets contrast. There are some, and quite probably many, such languages in which phonemic high [-ATR] and mid [+ATR] vowels are not very robustly distinguished in terms of formant values (due to heavy overlap of formant values for the two sets) (Casali 2008, Starwalt 2008), but in which the two sets remain distinct, due to differences in voice quality, even in the absence of cues from vowel harmony (which, valuable though they may be, are not necessarily available in all contexts). In Nawuri, for example, the verbs [lǒ:?] 'to enter' and [lǒ:?] 'to weave' are clearly distinguishable when pronounced in isolation despite their identical tone contours and consonantal sequences and despite very heavy overlap in formant values of their vowels (Casali 2002a). ${ }^{4}$

The extent to which both articulatory tongue root mechanisms and voice quality differences are in fact manifested in seven-vowel systems is a question whose answer is not very clearly known at present. The question has received extremely little explicit attention on the whole, with the most notable exception, by far, being an important (if not fully conclusive) study by Starwalt (2008). What must suffice for our present purposes is the recognition that the phonetic quality,

4 A natural and important question to pose concerning languages with such impressionistic differences in voice quality is the question of what their acoustic correlates are, and whether these are easily amenable to acoustic analysis using software tools such as Praat (http://www.fon.hum.uva.nl/praat/). As clearly revealed in a very extensive study by Starwalt (2008), the problem is an enormously difficult and complex one. (See also Casali 2008: 507-511.) Various possible acoustic measures have been explored in a number of studies (e.g., Hess 1992; Fulop et al. 1998; Guion et al. 2004), with mixed results. Among the more promising measures on the whole (Starwalt 2008) are first formant bandwidth (especially when adjusted to compensate for predicted effects of $F_{1}$ value; see Starwalt for discussion) and spectral center of gravity. However, the problem of finding a simple acoustic measure that consistently and reliably correlates, for all speakers, with voice quality differences that are reportedly audible has not been fully solved. The most useful conclusion is that the problem needs further study. 
with respect to tongue root position, of Height 2 vowels in a seven-vowel system is not necessarily analytically indeterminate or one that can be resolved only through instrumental studies based on ultrasound or similar technologies. Rather, it is at least in principle amenable to impressionistically-based analysis, even if the relevant judgments might well prove quite difficult in practice. ${ }^{5}$

Third, criteria that might be used to categorize Height 2 vowels in a seven-vowel language as either [+ATR] [e], [o] or [-ATR] [I], [v] are not limited to phonetic ones. Potential diagnostics involving phonological patterning exist as well. One clearly relevant phonological pattern, discussed in Casali (2003: 328-329) is common in seven-vowel languages of the type in (1c), including, for example, Kinande (Archangeli \& Pulleyblank 2002, Mutaka 1995), Lubwisi (Tabb 2001) and Kirangi (Stegen 2000). This pattern involves realization of mid [-ATR] vowels / / /, / / as allophonic [+ATR] variants [e], [o] in contexts where they precede and/or follow (depending on the language) [+ATR] vowels $/ \mathrm{i} /, / \mathrm{u} / \mathrm{.}$. In such languages, there are productive alternations in morphemes with mid vowels, with [-ATR] [ع] or [o] occurring in general, and a variant [e] or [o] occurring when the morpheme occurs in the neighborhood of a morpheme with $/ \mathrm{i} / \mathrm{or} / \mathrm{u} /$, as in the Kinande examples (adapted, with only notational changes, from Mutaka 1995: 48) in (3) below. (Here / $\varepsilon-/$ is an augment or "pre-prefix", /rI-/ is an infinitive marker, /-i/ is a causative suffix, and $/-\mathrm{a} /$ is the final vowel. Low tone is unmarked.)
a. $/ \varepsilon-$ rI-sck-i-a/ $\quad \rightarrow \quad[$ erisekia]
'to cause (someone) to laugh'
(compare [criscka] ' to laugh')
b. $/ \varepsilon$-rI-sok-i-a/ $\rightarrow \quad$ [erísokia]
'to cause (someone) to cross'
(compare [crisoka] 'to cross')

In cases of this sort, a language will have a full set of nine vowels [i i e $\varepsilon$ a $\supset$ o $v \mathrm{u}$ ] on the surface, though two of the vowels, [e] and [o], are non-contrastive. Since nine distinct vowels occur on the surface, with their distributions governed by [ATR] harmony, the problem of accurately determining the phonetic quality of each of the nine phonetically distinct surface vowels is no more difficult than the analogous problem in languages that have phonemic ninevowel /i i e $\varepsilon$ a $\supset$ o $v \mathrm{u} /$ systems. Once the nine surface vowel qualities have been clearly identified, and once it has been established that the vowels [e], [o] are predictable allophones of $/ \varepsilon /, / \supset /$ in $[+A T R]$ contexts, it can be unambiguously concluded that the phonemic inventory is a seven-vowel system of the type in (1c). That is, it is entirely clear that the predictable (hence phonemically missing) vowels are mid [+ATR] [e], [o], and hence it follows that the seven contrastive vowels must be the remaining seven, i.e., /i i $\varepsilon$ a $ว$ o $v \mathrm{u} /$.

The mirror image of this process, which is logically possible in the other type of seven-vowel system, in (2), would be one in which high [+ATR] vowels /i/, /u/ have allophonic variants [I], [v] derived through assimilation to non-low [-ATR] vowels $/ \varepsilon /, / \mathrm{s} /, / \mathrm{a} /$. Though not very common in

5 It is worth noting here that phonetic fieldwork carried out in earlier time periods, prior to the widespread availability of many of the investigative tools in use today, sometimes achieved remarkably detailed and accurate conclusions about tongue root contrasts based on non-instrumental techniques, e.g., Pike (1967) and Stewart (1967). This work essentially succeeds in accurately identifying, without the aid of instruments, the role of tongue root and pharyngeal cavity expansion mechanisms in Akan, anticipating the results of instrumental studies (e.g., Lindau et. al. 1972, Painter 1973). 
overall terms, such a pattern occurs in several Yoruba dialects, including Akure, Ifaki, Ijesa, and Ekiti (Casali 2003: 325, 328 George 1973, Oyelaran 1973, Przezdziecki 2005). By reasoning that is exactly analogous to that used above in the case of systems of the Kinande type, the existence of nine clearly identifiable and phonetically distinct surface vowels in such languages, two of which are readily analyzable as predictable [-ATR] allophones of $/ \mathrm{i} /$ and $/ \mathrm{u} /$, makes it clear that the seven vowels whose distribution is contrastive must be the other seven, /i e $\varepsilon$ a $\rho$ o $\mathrm{u} /$.

Static root-internal vowel co-occurrence patterns can also provide phonological evidence bearing on the question of which type of seven-vowel system is found in a language. Seven-vowel languages often show co-occurrence patterns in which Height 2 vowels are prohibited from cooccurring root-internally with either Height 1 vowels or Height 3 vowels (but generally not both). A very plausible assumption in the absence of clear evidence to the contrary is that such cooccurrence restrictions are the consequence of ATR harmony. Thus, it is natural to suppose that a language (e.g., Lubwisi; Tabb 2001), in which Height 2 and Height 1 vowels cannot co-occur while Height 2 and Height 3 vowels can, is a seven-vowel system of the type in (1c), with the inability of Heights 1 and 2 to co-occur being due to ATR harmony of an entirely familiar sort: as high [-ATR] vowels, Height 2 [I], [U] do not co-occur with high [+ATR] Height 1 vowels [i], [u]. In contrast, co-occurrence patterns in a language like Yoruba, in which Height 1 and Height 2 vowels freely co-occur while Height 2 and Height 3 vowels do not, are plausibly analyzed as due to ATR harmony involving [+ATR] Height 2 vowels [e], [o] and [-ATR] Height 3 vowels [c], [o] (Archangeli \& Pulleyblank 1989). (Co-occurrence of Heights 1 and 2 in Yoruba is fully expected if both heights involve [+ATR] vowels, as predicted.)

This simple picture is complicated to some extent by the possibility that co-occurrence restrictions involving Height 2 vowels could in some cases be due to harmony involving the feature [high] (Hyman 1999). However, the possibility of tongue root harmony restrictions is one that might certainly be entertained, especially in view of how common and widespread such restrictions are in African languages. The point here, in any case, is not that application of criteria based on co-occurrence patterns, or any other phonological criteria, need always be entirely straightforward in practice. As with other non-trivial phonological issues, challenging analytical cases may well arise in practice, and arguments based on fairly subtle criteria may be necessary.

Fourth, it is important not to overstate the degree to which disagreement or uncertainty over the phonetic identity of Height 2 vowels in a seven-vowel language has arisen in practice. While there certainly are cases in which a particular seven-vowel language has been analyzed by different researchers as having a different type of seven-vowel system (see Hyman 1999), it is also highly significant, in my view, that there are large regions in Africa in which analyses of sevenvowel systems in the same, or in closely-related, languages by different scholars have been remarkably consistent and convergent. It is striking, in particular, that, with only extremely rare exceptions (Kpelle and Eastern Nawdm being the only such cases known to me at present; see Casali 2003: 330), virtually all seven-vowel systems in West Africa have been analyzed as the type in (2), rather than the type in (1c). Even if we allow for a certain natural default bias (due to typographic and/or orthographic influences) toward transcription of Height 2 vowels as [e], [o] rather than $[\mathrm{I}],[\mho]$, it seems extremely implausible to suppose that such a high degree of agreement can be entirely explained in such terms. A simpler and more plausible explanation is the obvious one that seven-vowel systems in West African languages are overwhelmingly of the type in (2) and that linguists working in the region (who will in many cases have been quite familiar with the difference between high [-ATR] and mid [+ATR] vowels as manifested in various nine-/ten-vowel 
languages) have found little or no clear phonetic or phonological justification for positing the alternative seven-vowel system in (1c). Such a conclusion also finds support in various historical and comparative studies (Elugbe 1983, Ford 1973, Painter 1972, Stewart 1970, Williamson 1983). These studies have proposed that many seven-vowel systems in West Africa have resulted from earlier nine-/ten-vowel systems by the historical loss of /I/ and / $/$ / and, in the case of an original ten-vowel system, a low [+ATR] vowel /ạ/ as well), retaining only the vowels /i e $\varepsilon$ a $\rho$ o u/.

Finally, I think it is fair to point out that the assumption that seven-vowel ATR harmony systems subdivide into the two types in (1c) and (2) is a reasonable and natural one on a priori grounds. Given that there are languages in which tongue root position is contrastive in both high and mid vowels, it is entirely reasonable to expect that there might be languages (those of the type in (1c)) in which it is contrastive only in high vowels as well as languages (the type in (2)) in which it is contrastive only in mid vowels. This natural assumption is implicit or explicit in a great deal of theoretical and typological work on ATR harmony systems (Archangeli \& Pulleyblank 1989, 1994, 2002, Bakovic 2000, Calabrese 1995, Hyman 1989, Leitch 1996, Mutaka 1995, Orie 2003, Pulleyblank 1996, among many others), and it has been adopted, at least implicitly, in many analyses of individual seven-vowel languages. This does not, of course, guarantee that the assumption will turn out to be correct. However, it is at least reasonable to adopt it as a research hypothesis to see here it might lead, taking care to exclude cases of languages whose vowel systems are clearly in doubt. Where such a strategy is followed, we find that languages that have been described as of the /2IU/ seven-vowel type in (1c) and those that have been described as of the /1IU/ type in (2) show some non-trivial differences in their phonological patterning, and this is something that must ultimately be explained, in one way or another.

\section{Assimilatory dominance in /2IU/ and /1IU/ systems}

The survey results reported in Casali (2003) reveal an asymmetric picture in which dominance of [+ATR] vowels is highly characteristic of /2IU/ but not /1IU/ languages. In what follows, I summarize the essential generalizations described in that earlier study, and illustrate relevant patterns with examples drawn from various languages. The treatment here will be relatively brief and general (for details see Casali 2003).

Several forms of [+ATR] dominance are well attested in /2IU/ languages. One of the most common and familiar, attested in 34 of the /2IU/ languages surveyed in Casali (2003), is spreading from a dominant [+ATR] suffix. Such a pattern can be illustrated by the Kinande examples in (3) above, and also by the Diola-Fogny examples (adapted from Sapir 1965) in (4) below, which show two verbs with inherently [-ATR] vowels as they are pronounced in isolation (leftmost column) and when followed (rightmost column) by a dominant [+ATR] reversive suffix /-ul/ (in (4a)) or directive suffix /-um/ (in (4b)).

(4) $[$-ATR $]$ verb in isolation

With $[+$ ATR] suffix

a. [lo:p] 'to have a cord tied around the neck' [lo:p-ul]

b. [lib] 'to make slices'

[lib-um]

Also well attested in /2IU/ languages is spreading of [+ATR] across word boundaries (found in 11 languages surveyed in Casali 2003) or between roots in a compound word (found in 13 survey 
languages). The former pattern is illustrated in (5) with examples from Akan (adapted from Kügler 2015: 193-194).
a. /ketc bebree/ $\rightarrow$
[kغ̀té bèbrèè]
'many mats' mats many
b. /koto du/
$\rightarrow \quad[$ kótó dú $]$
crabs ten
'ten crabs'

[+ATR] spreading in compounds is illustrated in (6) with examples (Cahill 2007: 187, 444, 449,450 ) from Konni (Gur, Ghana). In these examples, the vowel(s) in the final syllable of an inherently [-ATR] noun root (shown as it appears in a minimal citation form in the leftmost column) becomes [+ATR] when followed by a [+ATR] adjectival root [bín] 'small $(6 \mathrm{a}, \mathrm{b})$ or [ní!ín] 'female' (6c).

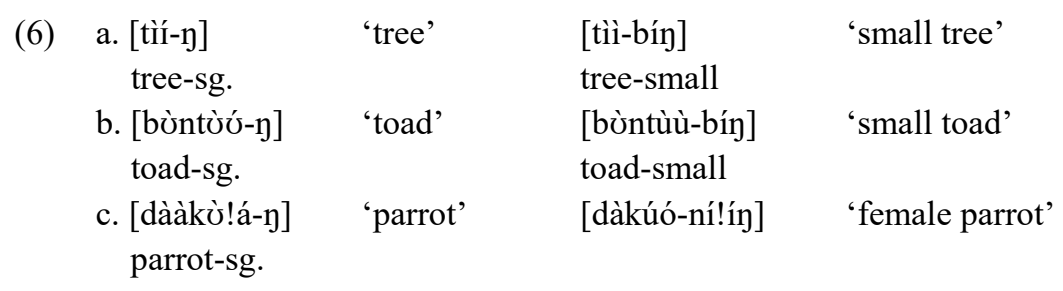

Many /2IU/ languages also display a kind of pattern, termed allophonic [+ATR] dominance in Casali (2003), in which a [-ATR] vowel that lacks a direct phonemic [+ATR] counterpart has an allophonic [+ATR] variant that occurs only in the context of neighboring [+ATR] vowels (where its [+ATR] surface value is potentially attributable to assimilatory spreading of [+ATR]). One pattern of this type, noted above, involves realization of mid [-ATR] vowels $/ \varepsilon /, / \mathrm{s} /$ as conditioned [+ATR] variants [e], [o] in the neighborhood of [+ATR] vowels $/ \mathrm{i} /, / \mathrm{u} /$ in a number of sevenvowel /i i $\varepsilon$ a $\supset$ $\mho \mathrm{u} / / 2 \mathrm{IU} /$ languages, such as Kinande.

Still more commonly, a good number of nine- or seven-vowel /2IU/ languages display a pattern in which the low vowel /a/ has a [+ATR] allophone derived via assimilation to neighboring [+ATR] vowels. Such a pattern occurs in Anum, for example, as shown in the forms in (7), adapted from Obeng (1995). (As elsewhere in this paper, the symbol [a] is used here to represent a low [+ATR] vowel.)
a. $/$ naa-dzil $\rightarrow$ [nąądzi]
'let him/her at'
b. /apraku/ $\rightarrow \quad[$ apraku]
(proper name)
c. /a-tu/
$\rightarrow \quad$ [atu]
'let him shoot'

Twenty-two cases of allophonic [+ATR] dominance in /2IU/ languages are noted in Casali (2003).

A further indicator of [+ATR] dominance found in some /2IU/ languages (including Chumburung, Ebira, Foodo, Gichode, Kabiye, Krachi, Nawuri, Talinga-Bwisi and Tem) involves systematic preservation of [+ATR] in cases where adjacent underlying vowels of opposite [ATR] values undergo vowel coalescence or merger. In Gichode, for example, a low or mid $\mathrm{V}_{1}$ and high $\mathrm{V}_{2}$ that come together across a word boundary regularly coalesce to form a mid vowel that retains the [back] and [round] features of $V_{2}$ (Casali 1996, based on field notes by Keith Snider). Where 
such mergers involve input vowels of opposite [ATR] values, the output vowel is always [+ATR], regardless of which of the two input vowels, $V_{1}$ or $V_{2}$, is underlyingly [+ATR]. The pattern is illustrated by a few Gichode examples (Casali 1996: 169-169) below. (The vowel resulting from merger is underlined.)
a. /dzono Ilo/
$\rightarrow$
[dzonelo]
'dog's sores'
b. /diga idzo/ $\rightarrow \quad$ [digedzo]
'young man's yams'
c. /atanatfise itfin/ $\rightarrow \quad$ [atanatfisetfin]
'female twin's veins'

Finally, many /2IU/ languages (e.g., Abouré, Akposso, Anyi, Anywak, Burun, Ega, Emalhe, Kirangi, Kusuntu, Lama, Nkonya, Talinga-Bwisi, Tem, Tepo and Turkana) display a type of pattern, termed weak assimilatory [+ATR] dominance in Casali (2003), in which one or more affixes that harmonize for [ATR] in some contexts also fail to harmonize in certain other contexts, in which they surface invariably in a [-ATR] form. For example (see Section 5.1 below), many /2IU/ languages have pronominal morphemes that harmonize for [+ATR] when affixed to a verb but are consistently [-ATR] elsewhere (for example, in their independent or citation forms). In Akan, for example, subject pronoun prefixes regularly harmonize for [ATR] with a following verb root, as shown for the prefixes in the forms in (9) (from Casali 2012: 36).

$\begin{array}{ll}\text { (9) mí-dà } & \text { 'I sleep' } \\ \text { b. wú-dà } & \text { 'you (sg.) sleep' } \\ \text { c. mí-dì? } & \text { 'I eat' } \\ \text { d. wú-dì? } & \text { 'you (sg.) eat' }\end{array}$

These pronouns can also occur as unbound forms, however, for example as a single word answer to a question. In this case, they surface with [-ATR] vowels (as [mí] and [wú] respectively). The same is true of the other personal pronouns in Akan, and indeed it is quite common to find in /2IU/ languages that morphemes that harmonize for [ATR] in certain contexts are [-ATR] when harmony fails to apply. In at least some theoretical approaches, the [-ATR] form could be treated as its inherent or underlying form. If so, then the [+ATR] form the same affix acquires in cases where it assimilates to a [+ATR] root can naturally be seen as an instance of [+ATR] spreading. ${ }^{6}$

In all, 69 /2IU/ languages which manifest some form (and often multiple forms) of [+ATR] dominance are reported in Casali (2003). It seems quite clear that assimilatory dominance of [+ATR] vowels is highly characteristic of /2IU/ systems.

6 From an OT perspective, there is another way of looking at the "weak assimilatory [+ATR] dominance" cases. In many actual patterns of this type the [-ATR] value taken by harmonizing affixes in contexts where harmony is inapplicable is plausibly indicative of a systematic prohibition against [+ATR] vowels in the relevant non-harmonizing context. The generalization that [+ATR] vowels are disallowed in a particular context must of course somehow be captured. In a standard OT model assuming Richness of the Base, this cannot be done by some constraint on underlying forms, and must be handled instead by some constraint ranking which guarantees that if underlying [+ATR] vowels did occur in the relevant context, they would not be permitted to surface as [+ATR] vowels. Cases of this type can be seen as instances of positional neutralization (see Section 5.1 below). 
The same cannot be said of assimilatory dominance of [-ATR] vowels. Limited cases of superficial [-ATR] dominance are found in some /2IU/ languages. However, as discussed at length in Casali (2003), such patterns generally have a marginal character, occurring only in highly restricted circumstances, ${ }^{7}$ and are often accompanied in the same language by more productive and regular [+ATR] dominance in other contexts. /2IU/ languages in which [-ATR] plainly functions as the regularly dominant value are not clearly attested. ${ }^{8}$

Since [+ATR] dominance is so highly typical of /2IU/ systems, it would be entirely natural to anticipate that the same should be true of /1IU/ systems as well. Virtually all of the manifestations of [+ATR] dominance that are well attested in /2IU/ systems are logically possible (and, seemingly, entirely natural) in /1IU/ systems as well, and there is no obvious reason, within most theoretical frameworks, why the absence of a tongue root contrast in high vowels (the sole essential respect in which /1IU/ systems differ from /2IU/ systems) should lead to a different propensity for assimilatory spreading of [+ATR]. Surprisingly, however, the natural expectation that [+ATR] dominance should be highly typical of /1IU/ systems as well is not borne out in actuality. In fact, it proves rather difficult to find clear cases of [+ATR] dominance in /1IU/ systems at all. Of 38 /1IU/ languages examined in Casali (2003), only a single /1IU/ language, Legbo (based on unpublished data from Larry Hyman), shows any form of [+ATR] dominance. Legbo has instances of both [+ATR]-preserving coalescence and weak assimilatory [+ATR] dominance, involving a subject pronoun that harmonizes for [ATR] in certain contexts but is [ATR] elsewhere. ${ }^{9}$ (See Casali 2003: 335 for examples and discussion.)

More recently, another potential case of a /1IU/ language with [+ATR] dominance has come to light. The harmony system of Ikoma (Higgins 2011), a seven-vowel /i e $\varepsilon$ a $\rho$ o u/ Bantu language of Tanzania, has some apparent instances of [+ATR] dominant suffixes. ${ }^{10}$ If the Legbo and Ikoma cases are taken at face value, then we must conclude that the absence of [+ATR] dominance in /1IU/ systems is not an absolute universal. Nevertheless, it is quite clear that /1IU/ and /2IU/ systems behave very differently in their overall propensities for [+ATR] dominance. [+ATR]

7 Marginal cases of [-ATR] dominance in languages in which [+ATR] is more regularly dominant have sometimes been discussed, particularly within work that assumes a general OT perspective, under the term dominance reversal, first introduced by Bakovic (2000). In essence, dominance reversal involves cases in which the non-optimality of a [+ATR]-dominant outcome that might otherwise be expected in a language is plausibly attributable to well-motivated independent and context-specific factors (i.e., factors unrelated to general dominance of [-ATR]) encoded as highly ranked constraints. If harmony constraints are also inviolable, superficial dominance of [-ATR] vowels can be forced under specific circumstances as a kind of last resort. (See Bakovic 2000, Casali 2002b, 2003:344-349, Hyman 2002, Sasa 2007 for discussion.)

8 The most viable (and, arguably, the only seemingly viable) case presented in Casali (2003) of a /2IU/ language in which [-ATR] is systematically dominant is the Bantu language Kimatuumbi, described in Odden (1996). See Section 5.1 below for some discussion of the Kimatuumbi case. I argue there that there are reasonable grounds for questioning the conclusion that Kimatuumbi's vowel inventory is in fact a /2IU/ system.

9 The survey included only languages that manifest some form(s) of superficial [+ATR] and/or [-ATR] to begin with. Since none of the 38 languages except Legbo displays [+ATR] dominance, this means that the remaining 37 languages actually display dominance of [-ATR] vowels in some context(s). Manifestations of [-ATR] dominance in /1IU/ systems are discussed directly below.

10 Higgins (2011) suggests, however, that the relevant patterns might also be amenable to an analysis in terms of dominance reversal (with [-ATR] being the systematically dominant value); other considerations argue that [-ATR] vowels are distributionally marked in Ikoma, and also appear superficially dominant in at least one context. The full range of facts is complex. 
dominance is ubiquitous in /2IU/ languages, but scarcely reported at all in /1IU/ languages (which are extremely common in overall terms). This difference, which is not clearly anticipated by most current theories, is a very surprising one that ultimately calls for some explanation.

Whereas clear evidence of [+ATR] dominance is not very well-attested in /1IU/ systems, certain indicators of [-ATR] dominance are much more strongly attested. Indeed, to the extent that evidence of asymmetric dominance of one or the other tongue root feature value is found at all in /1IU/ systems, evidence far more commonly implicates [-ATR] as the spreading value. This is not to say that the patterns that are observed in /1IU/ systems are the exact mirror image of those found in /2IU/ systems. We do not find numerous cases of dominant [-ATR] suffixes or of spreading of [-ATR] across word boundaries or in compounds. ${ }^{11}$ We do, however, find that [ATR], and not [+ATR], is commonly preserved in patterns involving coalescence of adjacent [+ATR] and [-ATR] vowels. Thus, coalescent realizations such as $/ \mathrm{a}+\mathrm{e} />[\varepsilon], / \varepsilon+\mathrm{o} />[0]$, or $/ \mathrm{a}+\mathrm{i} /$ $>[\varepsilon]$ are found in various /1IU/ languages. A few examples (from Awobuluyi 1972) illustrating [-ATR]-preserving coalescence in Owon Afa (Defoid, Nigeria) are shown below.

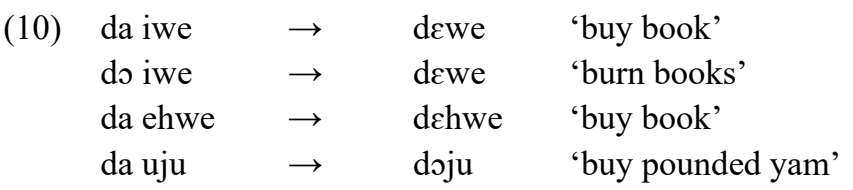

In all, 20 cases of [-ATR]-preserving coalescence in /1IU/ languages are reported in Casali (2003), ${ }^{12}$ as against only one /1IU/ language (Legbo, as noted above) with [+ATR]-preserving coalescence.

In addition, a number of /1IU/ languages (12 cases are noted in Casali 2003) manifest a type of pattern, referred to as weak assimilatory [-ATR] dominance in Casali (2003), that is essentially the mirror image of weak assimilatory [+ATR] dominance discussed above. That is, certain affixes that harmonize for [ATR] in some contexts are consistently [+ATR] in non-harmonizing contexts. In the seven-vowel /i i $\varepsilon$ a $\rho \mho \mathrm{u} /$ Bantu language Komo (Thomas 1992), for example, a mid vowel in several noun class prefixes will surface in a [-ATR] form before a root whose first vowel is a mid [-ATR] vowel $[\varepsilon]$ or [o], but in a [+ATR] form before any of the remaining vowels in the language, i.e., a high vowel [i] or [u], the low vowel [a], or a mid [+ATR] vowel [e] or [o]. The examples in (11) and (12) below (from Thomas 1992) illustrate the behavior of one such prefix, a singular Class 5 prefix $[\mathrm{e}] \sim[\varepsilon]$.

(11) Komo Class 5 prefix before mid [-ATR] vowel [ع], [0]

11 Casali (2003) reports one case of a /1IU/ language with [-ATR] spreading across word boundaries (Mbosi Oléé; Fontaney 1989, Leitch 1996) and one case of a /1IU/ language with [-ATR] spreading in compounds (Standard Yoruba; Archangeli \& Pulleyblank 1989). Tuwuli (not discussed in Casali 2003), a /1IU/ language spoken in Ghana, has an apparent case (which may, however, be of marginal productivity) of a dominant [-ATR] suffix (Harley 2005:61). More recently, a clear case of a dominant [-ATR] suffix /$\mathrm{o} /$ has been described (Gambarage, to appear) in Nata, a /1IU/ Tanzanian Bantu language that is quite closely related to Ikoma.

12 For detailed discussion and examples of robust cases of [-ATR]-preserving coalescence in two particular /1IU/ languages, Anufo (Adjekum et. al. 1993) and Owon Afa (Awobuluyi 1972), see Casali (1996) and Causley (1999). 

a. $\varepsilon$-gembe
'giant pangolin'
b. $\varepsilon-6 o ́ k o ́ t i ́ ~$
'generation'

(12) Komo Class 5 prefix before [i], [u], [e], [o], [a]
a. e-títí
'a bird'
b. e-gugu
'a cloud'
c. e-senge
'a fruit'
d. e-somba
'ritual'
e. e-dáka
'tongue'

The example in (12e), in which the prefix surfaces disharmonically as [e] before the [-ATR] root vowel [a], is crucial here. Were it not for this example, we might propose that the [ATR] value of the prefix is simply determined by harmony with the root vowel. While such a generalization could be made to hold for the examples in (11) and in (12a-d), it fails in the case of (12e), however. Since the [+ATR] quality of the prefix vowel in this example cannot be the result of assimilation (since the prefix vowel is [+ATR] while the root vowel is [-ATR]), it is reasonable to take the vowel /e/ that surfaces in this example as the underlying form of the prefix. If so, then the [-ATR] vowel acquired before roots with a mid [-ATR] vowel, as in (11), can be attributed to [-ATR] spreading from the root vowel. In contrast, no [ATR] spreading need be posited in the case of the examples in (12), if the prefix vowel is inherently [+ATR] to begin with. Thus, from at least some theoretical perspectives, such cases can be taken as evidence of assimilatory spreading of [ATR]. (See Casali 2003: 313-316 for discussion.) It is striking that whereas weak assimilatory [+ATR] dominance is highly characteristic of /2IU/ systems, weak assimilatory [-ATR] dominance is highly typical of /1IU/ systems.

As discussed in Casali (2008: 520-527), the reasons why /1IU/ and /2IU/ systems show different characteristic dominance relations are not well understood; though various explanations have been proposed, none of them is necessarily without difficulties. And, as noted above, some apparent counterexamples (Legbo and Ikoma) exist to the generalization that [-ATR] is dominant in /1IU/ systems as well. Nevertheless, while legitimate questions can be raised both about its universality and the factors that might explain it, the generalization that /1IU/ and /2IU/ systems show different characteristic dominance relations (with [-ATR] dominant in the former and [+ATR] in the latter) is quite well supported as a strong cross-linguistic tendency.

\section{Co-occurrence of $[i],[u]$ with $[\varepsilon],[0]$}

A further potential difference, not discussed in Casali (2003), in the characteristic patterning of /1IU/ and /2IU/ systems involves root-internal co-occurrence possibilities for mid [-ATR] and high [+ATR] vowels. Many, and possibly most, /1IU/ languages permit at least some (and sometimes all) logically possible combinations of mid [-ATR] vowels [ع], [o] with high [+ATR] vowels [i], $[\mathrm{u}]$ in root-internal $\mathrm{VC}_{0} \mathrm{~V}$ sequences. This is the case quite generally in Bantu $\mathrm{C}$ languages (Leitch 1996), all of which permit some sequences in which mid retracted vowels precede high advanced vowels, and many of which permit sequences involving the opposite order as well. Other /1IU/ languages which permit mid [-ATR] and high [+ATR] to co-occur root- or 
stem-internally include Anufo (Adjekum et. al. 1993), DuRop (Kastelein 1994), Jowulu (Djilla et. al. 2004), Komo (Thomas 1992), Mbodomo (G. Boyd 1997), Ngbaka (Archangeli \& Pulleyblank 1994), Ogori (Chumbow 1982a,b), Jenaama (Lauschitzky 2007, in preparation), Turka (Suggett 2005), and Yoruba (Archangeli \& Pulleyblank 1989).

Since no systematic survey of such co-occurrence possibilities in /1IU/ (or other) languages has yet been carried out, as far as I am aware, conclusions about the extent to which high [+ATR] and mid [-ATR] vowels typically co-occur in such languages are tentative. I think it is quite likely, however, that such co-occurrence patterns will in fact prove to be highly typical of /1IU/ languages. At the least, it is fairly easy to find /1IU/ languages in which such co-occurrence is permitted, and much harder to find /1IU/ languages where [ $\varepsilon],[0]$ cannot co-occur with [i], [u]. The only cases of the latter type known to me at present are Ikoma (Higgins 2011), and some varieties of Yoruba, including Akure (Przezdziecki 2005) and Ekiti (Orie 2003). In the latter, the non-occurrence of $[\mathrm{i}],[\mathrm{u}]$ before $[\varepsilon],[0]$ root-internally is due in part to an allophonic process in

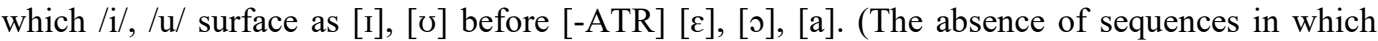
high [+ATR] [i], [u] follow $[\varepsilon]$ or [0] in Akure and Ekiti is not explicable in such terms, however, since the [I], [v] allophones occur only to the left of [-ATR] vowels in these languages.) In contrast, Ikoma is a rare case of a /1IU/ language in which there is reasonably clear evidence of [+ATR] spreading, as noted previously.

In /2IU/ harmony languages, on the other hand, root-internal co-occurrence of mid [-ATR] and high [+ATR] vowels in adjacent syllables is typically disallowed. That is, root-internal sequences involving only non-low vowels are generally harmonic in /2IU/ systems. ${ }^{13}$

The fact that co-occurrence of high [+ATR] and mid [-ATR] vowels is more readily tolerated in /1IU/ than /2IU/ systems need not be seen as simply a random finding, but can plausibly be viewed as a further manifestation of the generalization, discussed above, that different [ATR] values are characteristically dominant in the two systems. To see this, we can begin by considering an analysis of $/ 1 \mathrm{IU} /$ systems in which co-occurrence of $[\mathrm{i}]$, [u] with [ $[\varepsilon]$, [o] is permitted rootinternally. What must be explained, of course, is why disharmonic inputs involving mid and high vowels are not resolved by assimilation, given that sequences involving only mid vowels generally must be harmonic in /1IU/ systems (i.e., [+ATR] [e], [o] do not co-occur root-internally with $[-\mathrm{ATR}][\varepsilon],[0])$. It is quite natural to attribute disharmonic sequences combining high [+ATR] and mid [-ATR] vowels to the general absence in /1IU/ systems of high [-ATR] vowels [I], [ $\mho]$. If the vowels $/ \mathrm{i} /, / \mathrm{u} /$ were to undergo assimilation to neighboring mid [-ATR] vowels [ $\varepsilon]$, [0], this would

13 One possible exception to this statement that we might reasonably anticipate should exist involves the (comparatively uncommon) seven-vowel /i I $\varepsilon$ a $\rho ~ v \mathrm{u} /$ variety of /2IU/system. In such an inventory, in which mid [+ATR] vowels /e/, /o/ do not occur as phonemes, we might very naturally expect to find that $[\varepsilon],[0]$ might freely co-occur with $[\mathrm{i}],[\mathrm{u}]$. This is because $/ \varepsilon /, / \mathrm{J} /$ are phonemically unpaired in such a vowel system, and it is common in general for unpaired vowels to pattern as neutral vowels, capable of occurring with both harmony sets, in vowel harmony languages. Even in / i $\varepsilon$ a $\rho \mho \mathrm{u} /$ languages, however, co-occurrence of $[\varepsilon],[0]$ with [i], [u] is, as it turns out, very often not freely permitted. A good number of /2IU/ languages which have seven-vowel /i i $\varepsilon$ a $\rho \mho \mathrm{u} /$ languages (or the same basic system plus an additional central vowel) disallow mid [-ATR] vowels phonetically preceding and/or following high [+ATR] vowels, due to a process that realizes $/ \varepsilon /, / \mathrm{J} /$ as [+ATR] allophones [e], [o]. These include Burun (Andersen 1999), Daza (Kevin Walters, p.c., Connie Kutsch Lojenga, p.c.), Kinande (Archangeli \& Pulleyblank 2002, Mutaka 1995), Kirangi (Stegen 2000), Lese-Mvuba (Connie Kutsch Lojenga, p.c.), Lugbara (Andersen 1986), Lugungu (Kutsch Lojenga 1999), Mayogo ( McCord 1989) and Talinga-Bwisi (Paluku 1998, Tabb 2001). 
result in high [-ATR] vowels [I], [ひ], which are disallowed quite generally in such languages. Thus, by blocking the spread of $[-\mathrm{ATR}]$ to $/ \mathrm{i} /, / \mathrm{u} /$, a general and independently required constraint against the combination [+high,-ATR] is responsible for the fact that the vowels $/ \mathrm{i} /, / \mathrm{u} /$ are neutral and permitted to occur disharmonically with [-ATR] vowels. With some variation, this analysis attributing the co-occurrence of mid [-ATR] and high [+ATR] vowels in a /1IU/ system to a blocking effect of a markedness constraint against [I], [ひ] is found in a number of studies in optimality theory (Leitch 1996, Orie 2003, and Pulleyblank 1996).

As natural as this explanation is, however, it is not actually complete. While a general and well-motivated prohibition against high [-ATR] vowels [I], [ ] suffices to explain why /i/, /u/ do not assimilate to the [-ATR] value of $/ \varepsilon /, / 0 /$, it has nothing to say about a second possibility by which a disharmonic input such as $/ \varepsilon \mathrm{Cu} /, / \mathrm{iC} /$, etc. might be rendered harmonic: spreading of [+ATR] from $/ \mathrm{i} /$ or $/ \mathrm{u} /$ to $/ \varepsilon /$ or $/ \mathrm{o} /$, resulting in a fully harmonic output with only [+ATR] vowels (e.g, eCu, iCo, etc.). The failure of such spreading to occur cannot be easily attributed to the markedness of the output sequences that would result, since sequences combining high and mid [+ATR] vowels are entirely permissible and quite well-attested in nearly all /1IU/ systems. Moreover, we shall see evidence below that the mid [+ATR] [e], [o] vowels often pattern as unmarked relative to their [-ATR] counterparts in /1IU/ systems. As long as [+ATR] spreading is possible in general, it is not obvious why disharmonic inputs combining /i/, /u/ with $/ \varepsilon /, / \mathrm{s} /$ should not be rectified by such spreading. If, however, [+ATR] spreading is not in fact freely possible in /1IU/ systems, due to the fact that [-ATR] is the dominant value, then the pattern is entirely expected. [-ATR] does not spread due to a well-motivated prohibition against high [-ATR] vowels, while [+ATR], as the recessive value, simply does not spread at all. In /2IU/ systems, on the other hand, [+ATR] spreading very clearly is widely permitted, and thus the fact that the same root-internal co-occurrence of $[\mathrm{i}]$, [u] with $[\varepsilon],[0]$ is generally not permitted in such systems is unsurprising. That is, [+ATR] spreading would suffice to eliminate disharmonic sequences involving high [+ATR] and mid [-ATR] vowels in such systems.

Of course, it ultimately becomes necessary to explain why [+ATR] is typically not dominant in /1IU/ systems, as it is in /2IU/ systems. In the absence of an answer to this question, the explanation proposed above for why co-occurrence of $[\mathrm{i}],[\mathrm{u}]$ with $[\varepsilon]$, [o] is so freely tolerated in /1IU/ languages (but not, in general, in /2IU/languages) is incomplete. Attempting to explain why [-ATR], and not [+ATR], is characteristically dominant in /1IU/ systems is outside the scope of this paper (see Casali, in preparation). What must suffice for our present purposes is simply that co-occurrence possibilities involving these two classes of vowels constitute a further apparent difference in the typical patterning of the two systems and that the difference can be related to a difference (for which abundant evidence of other sorts exists) in the dominant [ATR] value in the two systems. Though there is more left to explain, these findings are relevant to the task of constructing an adequate typological picture (and, ultimately, theoretical account) of tongue root harmony systems.

Arguments that take co-occurrence of high [+ATR] and mid [-ATR] vowels to be an indicator that [-ATR], not [+ATR], is the spreading value can be found in various studies of /1IU/ tongue root harmony languages (e.g., Archangeli \& Pulleyblank 1989).The claim presented here, however, that the possibility of such co-occurrence represents a systematic difference in the patterning of /1IU/ and /2IU/ inventories has not been explicitly proposed in previous work, as far as I am aware. 
Before leaving this section, one further issue must be addressed. An anonymous reviewer for this journal has raised concerns over the extent to which the co-occurrence generalizations presented here might be impacted by the behavior of loanwords. This is a reasonable concern inasmuch as loanwords often behave differently with respect to phonological patterns and might plausibly be expected to pattern exceptionally with respect to harmony in some languages.

A practical obstacle to a fully detailed and comprehensive treatment of this issue is the fact that descriptive sources on tongue root harmony language often fail to explicitly discuss loanwords. Nevertheless, there are reasonable grounds to believe that the major conclusions presented above are unlikely to be significantly affected by possible differences in the harmonic patterning of loanwords.

Consider first the conclusion that has been argued to hold for /1IU/ systems, i.e., that cooccurrence of high [+ATR] and mid [-ATR] vowels is well attested in /1IU/ languages. This conclusion might be undermined if there were good reason to suppose that the reported cases of such co-occurrence owe their existence to the exceptional behavior of loanwords. However, there is no clear evidence in any of the descriptive sources consulted to suggest that this is the case. Rather, the most straightforward reading of these sources suggests that co-occurrence of high [+ATR] and mid [-ATR] vowels is possible in native roots in the languages described. Even if it should prove to be the case that loanwords give rise, in some of the languages, to additional cooccurrence possibilities, this would not affect the conclusion that co-occurrence of high [+ATR] and mid [-ATR] is frequently tolerated in /1IU/ systems.

The other major empirical conclusion is the one argued to hold of /2IU/ languages: that such languages typically do not freely tolerate co-occurrence of high [+ATR] and mid [-ATR] vowels. It is entirely possible that loanwords are exceptional with respect to this generalization in some cases. That is, we might conceivably find /2IU/ languages in which [i], [u] are able to co-occur with $[\varepsilon],[0]$ in loanwords, but not in native vocabulary. ${ }^{14}$ Should such a finding emerge, however, it would nevertheless remain true that co-occurrence of high [+ATR] and mid [-ATR] vowels is typically not possible in native roots in /2IU/ languages. Since we have reasonably good evidence that such co-occurrence frequently is possible (in native roots) in /1IU/ systems, we have an overall body of evidence that points, at least suggestively to a significant difference in the patterning of native forms in the two systems. If so, this is something that must be explained. And as we have noted, it is possible to make sense of the difference in terms of a general difference, for which other robust evidence exists, in the [ATR] value that is characteristically dominant in the two inventory types.

\section{Positional neutralization and markedness relations in non-low vowels}

A generalization which is not directly presented in Casali (2003), but for which a good case can be made, is that $/ 2 \mathrm{IU} /$ and /1IU/ systems show differences not only with respect to assimilatory dominance but in their characteristic markedness-related patterning as well. ${ }^{15}$ In fact, I will argue

14 It certainly cannot be taken for granted that loanwords will violate regular tongue root harmony patterns in a /2IU/ language. There are some /2IU/ languages (e.g., Chumburung, discussed in Hansford \& Hansford 1989) in which loanwords generally conform to the same tongue root harmony restrictions as native words.

15 Implicitly, potential arguments for differences in markedness relations in /1IU/ and /2IU/ systems can be found in the discussion of weak assimilatory [+ATR] dominance and weak assimilatory [-ATR] 
in what follows that we find reasonably strong evidence for essentially opposite markedness relations in non-low vowels in the two types of systems. Specifically, /2IU/ systems characteristically treat both mid and high [-ATR] vowels as unmarked relative to their [+ATR] counterparts, while the opposite relations appear to hold in /1IU/ systems, all of which clearly treat [-ATR] [I], [U] as marked relative to [+ATR] [i], [u], and at least some of which also treat [-ATR] mid vowels $[\varepsilon],[0]$ as marked relative to $[\mathrm{e}],[\mathrm{o}]$.

The claim that non-low vowels in /2IU/ and /1IU/ systems should conform to opposite markedness generalizations is a rather unexpected one on several counts. To begin with, relatively few phonological theories provide any clear reason to expect what might easily be regarded as a relatively minor difference in inventory structure (presence or absence of a tongue root contrast in high vowels) to entail such a striking difference (indeed reversal) of markedness relations. Moreover, such a finding does not square well with the widely held, and inherently quite reasonable, assumption that markedness relations in vowels (and consonants) are a reflection of phonetic substance. It is quite widely assumed that markedness of [ATR] values is assessed in conjunction with height feature values, and that marked combinations of the features [high], [low] and [ATR] are those whose production entails awkward and potentially antagonistic gestures (Bakovic 2000: 54-57, Bakovic \& Wilson 2000: 46-47, Archangeli \& Pulleyblank 1994, 2002, Calabrese 1995, Vaux 1996: 179, Wayment 2009: 45-46). Specifically, the combinations [+high,-ATR] and [+low, +ATR] are assumed to be highly marked (and to be targeted by markedness constraints, e.g., $*[+$ high,-ATR $]$ and $*[+$ low, + ATR $])$, in virtue of the fact that raising the tongue body (in producing a [+high] vowel) naturally tends to lead to an advanced tongue root position (favoring [+ATR], not [-ATR]), while lowering the tongue body naturally leads to tongue root retraction. In contrast, the combinations [+high, +ATR] and [+low, -ATR], which involve sympathetic gestures, are assumed to be unmarked; consequently, few if any contemporary theories have posited markedness constraints against these latter combinations. If the basis of tongue root markedness relations lies in such substantive factors, which have nothing to do with the structure of a language's vowel inventory, it is natural to expect that these relations should remain constant across inventories. We should presumably not expect to find, for example, that substantively favored high [+ATR] vowels [i], [u] should ever pattern as more marked than their substantively dispreferred [-ATR] counterparts [I], [v], let alone that such a state of affairs should prove to be highly characteristic of a particular type of inventory.

While a finding that a particular class of vowels should pattern as unmarked in one inventory but unmarked in another is not easily reconciled with widely held assumptions about the substantive bases of markedness relations in vowels. I argue below, however, that this is indeed what we find, at least in the case of non-low vowels. Markedness relations in /2IU/ inventories are treated in Section 5.1, while markedness relations in /1IU/ systems are discussed in Section 5.2.

5.1. Positional neutralization and markedness in /2IU/ systems. Although it has been assumed in recent work that [+ATR] is marked in non-high vowels and [-ATR] in high vowels, this is not the only view. A theme that can be found, to varying degrees of detail and explicitness, in some descriptively-oriented work on /2IU/ harmony languages from earlier decades is that [+ATR] vowels are marked as an entire class, while [-ATR] vowels are unmarked. Specifically, a tendency was noted in various /2IU/ languages for [-ATR] to function as a kind of default value, not just

dominance patterns presented in Casali (2003) (see Note 6 above). 
because [-ATR] vowels were observed to be targets, rather than triggers, of assimilatory spreading (though this is indeed often the case), but because [-ATR] vowels have a wider distribution than [+ATR] vowels. For example, Bole-Richard (1981) treats [-ATR] vowels as unmarked in Ega because the vowels of certain morpheme classes are consistently [-ATR] in contexts where harmony fails to apply, so that there are contexts in which only [-ATR] quality is possible. Other work which treats [-ATR] vowels as unmarked in /2IU/ languages, based at least in part on distributional criteria, includes Bole-Richard (1981), Dawson (1975), Kutsch Lojenga (1991) and Stewart (1967).

Although the view that [+ATR] vowels are marked as a class in $/ 2 \mathrm{IU} /$ systems has not been much discussed, let alone endorsed, in recent work, I will now argue that there is in fact quite good evidence to support it. Quite a number of /2IU/ languages have certain contexts in which [ATR] vowels, including high [-ATR] vowels, are permitted to the exclusion of any [+ATR] vowels.

One particularly well-attested kind of distributional restriction, found in many nine- or tenvowel /i I e $\varepsilon$ a (a) $\supset$ o $v \mathrm{u} /$, languages of West Africa, involves a pattern in which only [-ATR] vowels are found in the independent forms of pronouns. Typically, pronouns in such languages come in two forms: bound subject and object forms, which are affixed to verb stems (with which they usually harmonize and free forms that occur in other contexts (in which harmony is generally inapplicable), for example as a one-word answers to a question. In quite a few such languages, independent forms of pronouns contain only [-ATR] vowels. This is the case in Abouré (Burmeister 1982), Abron (Ravenhill 1982), Ahanta (Burmeister 1988), Akan (Casali 2012), Anyi (Burmeister 1988), Avatime (Schuh 1995), Bete (Werle \& Gbalehi 1976: 84), Dagara (Somé 1982), Chumburung (Hansford 1988, Snider 1990), Diola-Fogny (Sapir 1965), Ebira (Adive 1989), Efutu (Obeng 2008), Ega (Bole-Richard 1981: 47-48, 1982: 392-393), Gichode (Snider 1989a), Kabiye (Delord 1976), Konni (Cahill 2007), Krachi (Snider 1989a), Nawuri (Snider 1989a), Koromfe (Rennison 1997), Ngiti (Kutsch Lojenga 1994b: 200, 209), Tépo (Dawson 1975), and Vata (Kaye 1981, 1982).

It must also be noted that in all of these cases except one, the set of [-ATR] vowels found in pronouns includes the high [-ATR] vowels [I], [U]. (Avatime, whose pronouns contain only the non-high [-ATR] vowels $[\varepsilon],[\mathrm{a}],[0]$, is the lone exception.) This fact is relevant in view of the expectation of many current theories that high, but not non-high, [-ATR] vowels should pattern as marked sounds.

In fact, some /2IU/ languages permit only the high vowels [I], [U] and the low vowel [a] in independent pronouns and/or other contexts, as in Chumburung, for example, whose independent pronouns are shown below. 
(13) Chumburung independent pronouns (Hansford 1988, Snider 1990)

\begin{tabular}{|l|l|}
\hline Person \& number & Independent pronoun \\
\hline $1^{\text {st }}$ singular & {$[\mathrm{mó}]$} \\
\hline $2^{\text {nd }}$ singular & {$[\mathrm{fó}]$} \\
\hline $3^{\text {rd }}$ singular & {$[\mathrm{mò}]$} \\
\hline $1^{\text {st }}$ plural & {$[$ àní $]$} \\
\hline $2^{\text {nd }}$ plural & {$[$ mòní $]$} \\
\hline $3^{\text {rd }}$ plural & {$[$ bámó $]$} \\
\hline
\end{tabular}

The Chumburung pattern is readily intelligible as a combination of two independent markedness avoidance effects: avoidance of [+ATR] vowels (which excludes [i], [u], [e], [o] and [a]) and avoidance of mid vowels (which excludes [ع], [0], as well as the already excluded [e], [o]). That mid vowels can be systematically avoided in certain contexts is well known from other work on positional neutralization (Beckman 1997), and seems to be a fairly widespread pattern in Niger-Congo. Other /2IU/ nine-vowel languages which permit only the three vowels [a], [I], [v] occur in some class of function words include Konni (Cahill 2007: 13-14), Nawuri (author's own data, Snider 1989a) and Ngiti (Kutsch Lojenga 1994b).

Although pronouns are a common class of grammatical word in which [+ATR] vowels are absent in /2IU/ languages, some languages show avoidance of [+ATR] vowels in other function word classes as well. Such cases include

- Diola-Fogny (Sapir 1965), in which pronouns (1965: 70), prepositions (1965: 88-89) and sentence connectives (1965: 108-109) have only [-ATR] vowels,

- Ega (Bole-Richard 1981: 47-48), in which independent pronouns and conjunctions ("morphèmes relateurs") are invariably [-ATR],

- Kabiye (Delord 1976), in which personal pronouns, noun class markers in their nonharmonizing, pronominal uses (1976: 337), postpositions (1976: 370), nominalized possessive adjectives (1976: 348-349), and demonstrative forms constructed from noun class markers (1976: 355) all have only [-ATR] vowels,

- Lama (Ourso 1989: 157), in which pronouns and demonstratives in the noun class system have only [-ATR] vowels,

- Nawuri (author's own data, Snider 1989a), which has only [-ATR] vowels in independent pronouns and also demonstratives and determiners,

- Ngiti (Kutsch Lojenga 1994b), in which several classes of pronouns (1994b: 89, 200, 209) and demonstratives (1994b: 372, 375) as well as "postpositions functioning in the alienable possessive construction" (1994b: 154-157) have only [-ATR] vowels

- Talinga (Paluku 1998: 202-204), in which several types of demonstrative pronouns have only [-ATR] vowels.

- Bete (Werle \& Gbalehi 1976) and Ebira (Adive 1989), which permit only [-ATR] vowels in all function words.

Note that in all of these languages, high as well as non-high [-ATR] vowels are found in contexts in which all [+ATR] vowels are excluded. 
Other /2IU/ languages systematically neutralize tongue root contrasts to [-ATR] in some affixal contexts.

- In Akposso (Anderson 1999) and Emalhe (Laniran 1985), for example, leftward spreading of [+ATR] from a verb root affects only the prefix closest to the verb; prefixes to the left (including those with high vowels) are consistently [-ATR].

- In Kusuntu (Kleinewillinghöfer 1999, Ulrich Kleinewillinghöfer, personal communication), certain verbal prefixes harmonize for [ATR] with a following verb root in rapid speech but are pronounced in a [-ATR] form in slow speech.

- In Kalabari Ijo (Akinlabi 1997), prefixal clitics harmonize with verb roots, while suffixal clitics (including those with high vowels) are consistently [-ATR].

- In Koromfe (Rennison 1997), pronominal clitics (as well as independent pronouns), are always [-ATR].

It might seem surprising that (non-assimilatory) positional neutralization in affixes is not more common than it is, given that the root-affix distinction is one that is, in general, very commonly associated with positional neutralization. That such cases are relatively infrequent might be attributed at least in part to the fact that the tongue root value of affixes is so commonly determined by vowel harmony in most /2IU/ languages. That is, harmony considerations typically override whatever purely positional effects might otherwise occur. (See Casali 2003: 365f for some relevant discussion.)

It is also noteworthy that [-ATR] vowels occur with far greater frequency than [+ATR] vowels in many of the same languages (e.g., Chumburung, Diola-Fogny, Konni), in both lexical entries and running text, sometimes outnumbering them by a factor of three or four to one (Casali 2002a and references therein). While the consistent reliability of frequency as a diagnostic of markedness has been questioned (Hume 2011), it is certainly true that marked sounds occur much less commonly than unmarked ones.

The finding that non-high [+ATR] vowels might pattern as marked relative to their [-ATR] counterparts in /2IU/ languages is not unexpected under widely held assumptions about markedness. It is generally accepted that [+ATR] low vowels are marked, and a marked status for mid [+ATR] vowels is also often assumed (Archangeli \& Pulleyblank 1994, 2002, Calabrese 1995). However, the finding that high [+ATR] vowels [i], [u] should pattern as marked relative to their [-ATR] counterparts [I], [ช], and that tongue root contrasts in high as well as non-high vowels should be positionally neutralized to [-ATR] in many /2IU/ languages is much more surprising. Such a finding runs counter to standard assumptions, outlined above, about the substantive bases of tongue root markedness and the articulatory antagonism of tongue body raising and tongue root retraction. Moreover, it is surprising in light of the fact that the vowels [i], $[\mathrm{u}]$ are found in all known tongue root harmony languages, while [I], [ひ] are absent in many languages (i.e., those of the /1IU/ type).

Not only does the unexpected case in which high [-ATR] [I], [च] are more widely distributed than high [+ATR] [i], [u] in a /2IU/ language prove to be quite strongly attested, the far more expected case in which high vowel tongue root contrasts are positionally neutralized to [i], [u] in a /2IU/ language turns out not to be well attested. Potential cases are not common, and fully compelling cases are not very clearly attested at all. In what follows, I summarize the potential cases presently known to me. 
One apparent case that initially looks quite promising is discussed briefly in Calabrese (2005: 125). Citing a study by Omamor (1973), Calabrese describes Uvwie, an Edoid language of Nigeria, as having nine contrastive vowels /i I e $\varepsilon$ a $\rho$ o $\mho \mathrm{u} /$ in roots, but only the seven vowels /i e $\varepsilon$ a $\supset$ o $\mathrm{u} /$ in affixes. Since it is the two high [-ATR] vowels [I], [ ] that are systematically excluded in the latter context, such a pattern would be a case of positional neutralization of high vowel tongue root contrasts to [+ATR]. As it turns out, however, the generalization as described by Calabrese appears to be incorrect. While the original study does indeed state that high [-ATR] vowels are absent in Uvwie prefixes (Omamor 1973: 129), a later study, Omamor (1988), clearly describes Uvwie as having all nine vowels in both roots and affixes. Even in the 1973 paper, the conclusion that high [-ATR] affixes are absent in prefixes is not entirely unequivocal. The discussion of formant measurements (pp. 133-135) leaves open the possibility that high [-ATR] and mid [+ATR] vowels might be distinct in prefixes as well, though in the process of merging. Thus, Uvwie is not a compelling case of a language in which high vowel tongue root contrasts are positionally neutralized to [+ATR].

Another potential case of positional avoidance of [I], [ $\mathrm{\sigma}]$ in a /2IU/ language occurs in Bila, a nine-vowel /i i e $\varepsilon$ a $ว$ o $\mho \mathrm{u}$ / language of Democratic Republic of Congo (Kutsch Lojenga 1994a). While all nine vowel qualities contrast in verbs and in initial syllables of CVCV noun roots, the high retracted vowels [I], [ซ] do not occur in non-initial syllables of disyllabic noun roots. (All [+ATR] vowels are permitted in non-initial syllables as, are all non-high [-ATR] vowels.) Kutsch Lojenga does not discuss the distribution of vowels in great detail, but does note (1994a: 8) that "the verbal system clearly presents a nine-vowel system with cross-height [ATR] harmony." If it turns out that most verb roots in Bila, as in most Bantu languages generally, are maximally CVC, then the question of whether high [-ATR] vowels are able to occur in non-initial syllables of verb roots may well be moot, in which case it might be possible to maintain the simple generalization that $[\mathrm{I}],[\mho]$ do not occur in non-initial syllables of roots at all. Since the initial syllable of a root is a position that has been characterized as a prominent one (Beckman 1997) prone to licensing marked sounds (which may be prohibited elsewhere) the absence of [I], [U] in Bila non-initial syllables could be considered a case of positional avoidance of these vowels.

Kutsch Lojenga speculates, quite plausibly, that the Bila nine-vowel inventory is the result of a historical innovation from an earlier seven-vowel /i e $\varepsilon$ a $\rho \circ \mathrm{u} /$ inventory. If so, the current distribution of $[\mathrm{I}],[\mho]$ likely derives in part from somewhat unusual historical developments. Whether or not the distributional limitations on these vowels must also be treated as a synchronic markedness effect in a synchronic grammar is perhaps a harder question to answer, at least on entirely theory-independent grounds.

In two nine-vowel Cameroonian languages of Bantu Zone A, Mmala and Yangben, contrast between high [-ATR] vowels $/ \mathrm{I} /, / \mho /$ and their mid counterparts $/ \varepsilon /, / \mathrm{J} /$ is neutralized in closed syllables, in which only the latter occur (G. Boyd 2015). In both languages, this neutralization is the result of an active lowering process that gives rise to alternations, so that that the vowel of a verb root like the Yangben root /kot/ 'fasten, bind' surfaces with a high [-ATR] vowel when followed by a vowel (so that the root vowel occurs in an open syllable), as in (14a), but with a mid [-ATR] vowel when final (so that the root vowel occurs in a closed syllable), as in (14b).

(14) a. [kù-kưt-à]

b. [kù-kว̀t]

'to fasten' (with continuative suffix [à])

'to fasten' (unsuffixed) 
Contrast between high and mid [-ATR] vowels is maintained in open syllables in both languages, so that a form like (14a) above contrasts in Yangben with a form like [kò-sók-j̀] 'to extract (continuative)'. Aside from [I] and [ $\mathrm{\mho}]$, all other vowels are found in both open and closed syllables. To the extent that closed syllables might plausibly be argued to be a kind of nonprominent phonological position (e.g., because of a tendency for vowels to be of shorter duration in closed syllables), these findings might be viewed as an instance of positional avoidance of [I], $[\mho]$ in a weak position. However, it can be noted that the relevant phonological patterns involve active neutralization of a height contrast, rather than a tongue root contrast.

The only other potential case I am aware of is found in Kimatuumbi, described in Odden (1996). Kimatuumbi is described by Odden as a seven-vowel /i i $\varepsilon$ a $\supset$ $v \mathrm{u} /$ language. In noun class prefixes, only the three vowels [i], [u], [a] are permitted in non-assimilatory contexts. The nonoccurrence of mid vowels in such positions is a fairly common restriction in Bantu languages, and applies elsewhere in Niger-Congo as well. Of more relevance is the fact that the high advanced vowels [i], [u] are permitted to the exclusion of [I], [U]. Like the Uvwie pattern as described by Calabrese, this appears to be a case of positional neutralization of high vowel tongue root contrasts to [+ATR].

While there is no apparent ground for questioning the conclusion that the Kimatuumbi pattern involves positional neutralization of the contrast between its two highest vowels to [i], [u], there is at least some room for questioning whether the vowel system is in fact a /2IU/ system to begin with. If the Height 2 vowels were treated as [e], [o] rather than [I], [v], Kimatuumbi would be a $/ 1 \mathrm{IU} /$ /i e $\varepsilon$ a $\rho$ o $\mathrm{u} /$ system with a simple prohibition, for which there is much precedent in the patterning of other Bantu languages, against mid vowels in certain contexts. ${ }^{16}$

As discussed in Section 2 above, the problem of determining whether a particular seven-vowel languages is of the /i i $\varepsilon$ a $\rho v \mathrm{u} /$ or the /i e $\varepsilon$ a $\rho$ o u/ is not necessarily trivial, and it has sometimes been questioned whether it is in fact possible to reliably distinguish the two types. I argued in that section that the distinction between the two types is in fact meaningful and that non-arbitrary criteria that can in principle be brought to bear on the question. This does not guarantee, however, that the question will be easy to answer in every particular case. Seemingly ambiguous cases may very well arise in practice.

Although Kimatuumbi is treated (following Odden's description) as a /i i $\varepsilon$ a $\supset \mho \mathrm{u} / \mathrm{system}$ in Casali (2003), along with eleven other languages classified as of the same basic /i I $\varepsilon$ a (ə) $\supset$ $v$ u/ type, it is perhaps the only language of the twelve for which this classification is potentially open to question. In contrast to $/ \mathrm{i}$ i $\varepsilon$ a (ə) $\rho \circlearrowright \mathrm{u} /$ languages like Kinande (Archangeli \& Pulleyblank 2002, Mutaka 1995) or Zande (R. Boyd 1997), in which the surface occurrence of [e], [o] as allophones of $/ \varepsilon /, / \mathrm{J} /$ in [+ATR] contexts leaves little room for doubt that the height 2 vowels are /I/, /o/ (see Casali 2003: 328-329) and not /e/, /o/, Kimatuumbi has only seven vowels on the surface. Moreover, there is no phonological evidence that decisively favors the /i i $\varepsilon$ a $\supset$ $u$ u/ analysis over /i e $\varepsilon$ a $ว$ o u/. Neither does impressionistic phonetic evidence (Odden 1996: 5) appear to be decisive. ${ }^{17}$

16 As discussed in Casali (2003: 349-353), Kimatuumbi is also somewhat exceptional as a /2IU/ system in a second respect as well, which is that [-ATR] vowels appear to be dominant in assimilation processes. As we have noted, such behavior is not very typical of /2IU/ systems but is typical of /1IU/ systems.

17 Odden reports (1996: 5) that whereas he found the Height 1 ([i], [u]) and Height 2 ([I], [v]) vowels to be perceptually difficult to distinguish, Charles Kisseberth found it more difficult to distinguish the height 2 vowels from Height $3([\varepsilon],[0])$. In any case, the relative height of $[\mathrm{I}],[\mathrm{v}]$ and $[\mathrm{e}],[\mathrm{o}]$ is known to be quite 
It would certainly be premature to conclude with any certainty that Kimatuumbi is actually a seven vowel /i e $\varepsilon$ a $\rho$ o u/ language. On the other hand, it is not entirely clear that it must be treated as a /i i $\varepsilon$ a $\rho \mho \mathrm{u} /$ system either. It is thus not a completely compelling example of a /2IU/ language which positionally neutralizes high vowel tongue root contrasts to [i], [u].

Although room for uncertainty exists over the correct interpretation of some particular cases, the general trend is clear enough. Patterns in which both high and non-high [+ATR] vowels are distributionally restricted relative to their [-ATR] counterparts are very well attested in /2IU/ systems, to the point that positional avoidance of [+ATR] vowels can fairly be viewed as quite typical of such systems. Positional avoidance of [-ATR] vowels, at any tongue height, is much less clearly in evidence in /2IU/ languages.

5.2 Positional neutralization and markedness in /1IU/ systems. While there is good evidence that /2IU/ languages characteristically treat [+ATR] as marked in non-low vowels, it is clear that this generalization does not characterize /1IU/ systems. Plainly, high [-ATR] vowels [I], [ひ] are strongly avoided in /1IU/ languages. Most /1IU/ languages lack these vowels entirely, though in a few languages, e.g., Ijesa Yoruba (Oyelaran 1973, Orie 2003), [I], [ ] occur with a highly restricted distribution, as allophones of $/ \mathrm{i} /, / \mathrm{u} /$ in the neighborhood of non-high [-ATR] vowels [ $\varepsilon$ ], [0], [a]. In contrast, high [+ATR] vowels [i], [u] are freely tolerated and widely distributed in /1IU/ languages. It is thus clear that /1IU/ languages treat [-ATR] as marked, and [+ATR] as unmarked in high vowels. By itself, this generalization is both entirely familiar and unsurprising from the perspective of widely held assumptions about tongue root markedness. As far as high vowels are concerned, it is the behavior of $/ 2 \mathrm{IU} /$ systems that stands as the less expected finding with respect to widely-held views on markedness.

What is more noteworthy about markedness patterning in /1IU/ systems, however, is the behavior of mid vowels. Surprisingly, there are good indications that /1IU/ systems not only treat [-ATR] as the marked value for high vowels, but for mid vowels as well. This is less clearly expected, as it is often assumed that [+ATR] is marked in mid vowels (Archangeli \& Pulleyblank 2002, Calabrese 1995). And indeed, there is quite good evidence for this assumption for /2IU/ systems, as discussed above. /1IU/ languages show evidence of conforming to the opposite relation, however. At the least, /1IU/ languages in which mid [+ATR] vowels have a wider distribution than mid [-ATR] vowels are well enough attested.

Positional neutralization of the tongue root contrast in mid vowels to [e], [o] in certain contexts is a pervasive phenomenon in the seven-vowel /i e $\varepsilon$ a $\rho$ o u/ Bantu languages of Guthrie's Zone C (Leitch 1996). All known Bantu $C$ languages have some degree of tongue root harmony in mid vowels, with the extent of harmony varying in complex ways. In many Bantu $\mathrm{C}$ languages, however, there are certain contexts involving prefixes and/or suffixes in which mid vowel tongue root harmony fails to apply. Quite consistently in these languages, affixal mid vowels in nonharmonizing contexts show up as [+ATR] [e], [o] and not [-ATR] [ع], [o]. This generalization suggests that $[+\mathrm{ATR}]$ is functioning as the unmarked value in mid vowels in Bantu $\mathrm{C}$ languages.

In Bolia, for example, both nominal and verbal prefixes consistently fail to harmonize; mid vowels in prefixes are invariably [e] or [o] (Leitch 1996: 41; the original source is Mamet 1960). Some examples are shown in (15) (nouns) and (16) (verbs) below. (Acute accent indicates high

variable in languages in which the two sets contrast (Casali 2008: 507-511); in some such languages, [e], [o] are acoustically higher than $[\mathrm{I}],[\mathrm{v}]$. Thus, a finding that Height 2 vowels are relatively high auditorily is not incompatible with the assumption that they are [e], [o] rather than $[\mathrm{I}],[\mathrm{v}]$. 
tone, the wedge represents a rising tone, low tone is unmarked. Roots are italicized. The nonharmonizing [-e] suffixes in $(16 \mathrm{c}, \mathrm{d})$ are, respectively, an imperative motional suffix and an indicative present negative suffix. Both are assumed by Leitch to be/-e/ underlyingly, in view of the fact that they never alternate. The final vowel suffix in $(16 a, b)$ is a different morpheme, an imperative exhortative suffix, which Leitch takes to be underlyingly /a/. This suffix undergoes assimilation to a preceding vowel $/ \varepsilon /$, surfacing as $[\varepsilon]$ in (16b). It does not assimilate following an advanced stem vowel /e/ in (16a). See Leitch 1996 for detailed discussion.)
a. bo-nsćlé
'lezard gris commun'
b. bo-nsélé
'nudité'
c. bo-tómbo
'chasse-palanquin du chef en form de pirogue'
d. bo-tóndo
'toit'
a. kǒ-kel-a

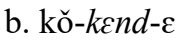
c. lo-yo-ksh-e
d. bá-pó-bong-é

'fais donc' (impérative exhortative)

'marche donc' (impérative exhortative)

'venez prendre' (impérative motional)

‘ils ne conviennent pas' (indicative présent négative)

Avoidance of mid retracted vowels in affixes occurs in Ikoma (Higgins 2011) as well. In Mono, a Ubangi language with a /ieaəi่วou/ system (treatable as a /1IU/ system due to the /o/ - / / contrast in back vowels, despite the absence of $/ \varepsilon /$ ), a fairly extensive set of pronouns contains only the three vowels [a], [e] and [ə] (Olson 2005). Finally, there are /1IU/ Bantu languages, including Bhele (Kutsch Lojenga 1994a), Mokpwe (Henson n.d.), Komo (Thomas 1992), Nata (Gambarage, to appear) and various Bantu C languages (see below for more discussion), in which mid affix vowels are [e], [o] except when they are attached to roots containing mid retracted vowels $[\varepsilon],[0]$, in which case they undergo [-ATR] spreading, surfacing as $[\varepsilon]$, [o]. Crucially, such affixes surface as [e], [o] in cases where the root vowel is /a/. Such a pattern is potentially analyzable as positional neutralization to $[+\mathrm{ATR}]$ quality in mid affix vowels that is overridden by mid vowel harmony requirements in cases where a root contains $[\varepsilon]$ or [0]. (See Gambarage, to appear, for a formal OT account of Nata harmony patterns along these lines.)

No systematic study of positional neutralization of vowel contrasts in /1IU/ languages presently exists, and it remains to be seen how common the Bantu-C-type neutralization patterns are in /1IU/ systems in general. Nevertheless, we have suggestive evidence of a further difference in characteristic markedness patterning in /1IU/ systems, and one that is plausibly related to a different marked tongue root feature value, [-ATR]. I am not aware of any /2IU/ systems in which the vowels [e], [o] exhibit the kind of unmarked, default-like, patterning seen in Bantu C. ${ }^{18}$

To summarize the findings of this section, positional neutralization patterns provide evidence of different markedness relations in non-low vowels in /2IU/ and /1IU/ systems. /2IU/ systems characteristically neutralize tongue root contrasts in both high and mid vowels to [-ATR],

18 An interesting case of a /1IU/ language, Gengbe, in which the vowel [e] is very widely distributed and functions in certain respects as a kind of default vowel is discussed in Abaglo \& Archangeli (1989). The arguments presented are to some extent theory-dependent and must probably be seen, from the perspective of more recent theories, as suggestive at best. Nevertheless, the very wide distribution and seemingly default-like behavior of [e] in Gengbe is at least arguably indicative of an unmarked status; I am not aware of any /2IU/ language in which a mid advanced vowel [e] (or [o]) exhibits similar behavior. 
effectively treating [+ATR] as marked. In /1IU/ systems [+ATR] is clearly unmarked relative to [ATR] in high vowels (which are generally absent), and there is reasonably good evidence for unmarked patterning of [+ATR] mid vowels [e], [o] relative to their [-ATR] counterparts as well.

The opposite markedness relations for non-low vowels evident in the two systems are strikingly reminiscent of the opposite dominance generalizations that have been observed in previous work. Setting aside the matter (taken up below) of low vowel patterning, it is possible, in fact, to summarize the markedness and dominance relations presented above as follows: [+ATR] is both the marked and dominant [ATR] value in non-low vowels in /2IU/ systems, while [-ATR] is both the marked and dominant [ATR] value in non-low vowels in /1IU/ systems. Moreover, while space will not permit detailed discussion of the matter here (for which see Casali, in preparation), it is quite striking that, despite the very different, and essentially opposite, markedness and dominance relations we find in the two systems, both inventories show a connection between markedness and dominance which is entirely consistent with a traditional conception of markedness (Causley 1999, de Lacy 2006, Rice 2007), in that the dominant value is distributionally marked while the recessive value is unmarked.

\section{Patterning of low vowels}

The finding that non-low vowels show different, and essentially opposite, markedness relations in /1IU/ and /2IU/ systems raises the natural question of whether similar differences exist in the patterning of low vowels. If low vowel markedness relations in /1IU/ systems were simply the reverse of those found in /2IU/ systems, as appears to be the case for non-low vowels, we might expect to find, all else equal, that a low [+ATR] vowel [a] consistently patterned as an unmarked vowel in /1IU/ languages while a low [-ATR] vowel [a] patterned as a marked vowel. This would be a surprising finding, based on familiar assumptions about low [+ATR] vowels (which are certainly not all that common in any type of system). As will become clear below, it is not what we find. Nevertheless, we see evidence that while the markedness-related patterning of low vowels in /1IU/ languages is not the clear and simple opposite of what we find in /2IU/ systems, neither is it exactly the same. Rather, it is possible to identify several respects in which low vowels appear to pattern differently in /1IU/ languages.

In /2IU/ systems, the assimilatory and markedness-related patterning of low vowels conforms to some generalizations that appear to hold quite consistently and present few surprises. With respect to markedness, a low and phonetically retracted vowel [a] is found in all /2IU/ languages and patterns quite consistently as an unmarked segment, e.g., in having an unrestricted distribution. A low [+ATR] vowel [a], on the other hand, is entirely absent in many /2IU/ languages, though it occurs in others, either as a conditioned allophonic variant of /a/ in [+ATR] contexts (see Section 3 above) or as a contrastive phoneme. In the latter case, it typically shows characteristics expected of marked, rather than unmarked, sounds, i.e., in having a low overall frequency of occurrence and/or being subject to various distributional limitations (Casali 2002a: 31-32). And of course, allophonic low [+ATR] vowels in /2IU/ languages are also, by definition, subject to distributional restrictions (being permitted only in contexts where their [+ATR] quality is attributable to assimilatory spreading of [+ATR]), and can appropriately be treated as marked.

With respect to assimilation, there is no evidence that a low and phonetically advanced vowel [a] patterns as anything other than a [+ATR] vowel in its harmonic affiliation in /2IU/ languages, or that a low and phonetically retracted vowel [a] patterns as anything other than a [-ATR] vowel 
in its harmonic affiliation. A generalization that holds consistently of /2IU/ systems (and this is potentially important, as we shall see indications below that /1IU/ languages sometimes behave differently in this regard) is that affixes that alternate harmonically for [ATR] with root vowels show up in their [-ATR], and not their [+ATR], allomorphs with roots whose vowel is /a/. This behavior is illustrated below with examples from Nawuri (adapted from Casali 1995b, with minor changes to phonetic symbols to conform to IPA usage) showing a harmonizing singular noun class prefix [0] [o] with various non-low [+ATR] and [-ATR] root vowels in (17) and with the root vowel $[\mathrm{a}]$ in $(18)$

(17) Noun class prefix [0] [o] with non-low [+ATR] root vowels

$\begin{array}{ll}\text { o-bi } & \text { 'child/person' } \\ \text { o-bu } & \text { 'room' } \\ \text { o-ge:? } & \text { 'valley' }\end{array}$

Noun class prefix $[0] \sim[\mathrm{o}]$ with non-low $[-\mathrm{ATR}]$ root vowels

$\begin{array}{ll}\text { o-bo } & \text { 'hole' } \\ \text { o-bon } & \text { 'body of water' } \\ \text { o-f } \varepsilon & \text { 'broom' } \\ \text { o-t } \int \mathrm{I}: ? & \text { 'woman' }\end{array}$

(18) Noun class prefix [o] [o] with low root vowel [a]

$\begin{array}{ll}\text { o-kpa } & \text { 'path' } \\ \text { o-ka:? } & \text { 'end' } \\ \text { o-pa:? } & \text { 'guinea worm' }\end{array}$

All other harmonizing affixes in Nawuri also show up in their [-ATR] allomorphs with roots whose vowel is /a/. The same generalization characterizes affix harmony in many other /2IU/ languages as well. ${ }^{19} \mathrm{I}$ am not aware of any /2IU/ languages which pattern differently in this regard, i.e., in which the root vowel /a/ regularly conditions [+ATR] allomorphs of harmonizing affixes. ${ }^{20}$

19 This is the case in at least the following /2IU/ languages: Abouré (Burmesiter 1982), Ahanta (Ntumy 1997), Akan (Dolphyne 1988, Casali 2012), Akposso (Anderson 1999), Anum (Obeng 1995), Anyi (Burmeister 1988), Avatime (Schuh 1995), Bali (Kutsch Lojenga 1994a), Bila (Kutsch Lojenga 1994a), Bongo (Kilpatrick 1985), Budu (Kutsch Lojenga 1994c), Chumburung (Snider 1990), Deg (Crouch \& Herbert 2003), Degema (Kari 2007), Diola-Fogny (Sapir 1965), Ebira (Adive 1989, Scholz 1976), Efutu (Obeng 2008) Ega (Bole-Richard 1981), Emalhe (Laniran 1985), Foodo (Plunkett 2006), Gichode (Snider 1990), Gonja (Snider 1990), Igbo (Zsiga 1997), Igede (Bergman 1971), Izi (Meier et. Al. 1975), Jumjum (Andersen 2004), Kabiye (Delord 1976), Kalabari Ijo (Akinlabi 1997), Kinande (Mutaka 1995), Konni (Cahill 2007), Koromfe (Rennison 1997), Krachi (Snider 1990), Kuku (Cohen 2000), Kusuntu (Kleinewillinghoefer 1999), Lama (Ourso 1989), Lika (Kutsch Lojenga 2008a), Lubwisi (Tabb 2001), Lugungu (Kutsch Lojenga 1999), Lulubo (Andersen 1987), Luo (Swenson 2015), Maasai (Hamaya 1997), Malila (Kutsch Lojenga 2008b), Mayak (Andersen 1999), Ngiti (Kutsch Lojenga 1994b), Ninkare (Equipe de la S.I.L. à Guélwongo 1998), Nkonya (Peacock 2007), Nuni (Yago 1984), Päri (Andersen 1989), Tangale (Kidda 1993), Tem (Tchagbalé 1976), Turkana (Noske 1996), Uvwie (Omamor 1988), 
In all, the patterning of [+ATR] and [-ATR] low vowels in /2IU/ systems can be briefly summarized as in (19) below.

(19) Summary description of low vowel patterning in /2IU/ languages

\begin{tabular}{|c|c|c|}
\hline & {$[\mathrm{a}]$} & [a] $]$ \\
\hline Level of attestation & Found in all /2IU/ languages. & $\begin{array}{l}\text { Found in some } / 2 \mathrm{IU} / \\
\text { languages, either as an } \\
\text { allophone of /a/ or a separate } \\
\text { phoneme, but absent in many } \\
\text { others. }\end{array}$ \\
\hline Markedness & $\begin{array}{l}\text { Behaves like an unmarked } \\
\text { segment: typically occurs with } \\
\text { high frequency and wide } \\
\text { distribution. }\end{array}$ & $\begin{array}{l}\text { Behaves like a marked } \\
\text { segment: typically occurs with } \\
\text { low frequency and is often } \\
\text { subject to distributional } \\
\text { restrictions. }\end{array}$ \\
\hline Assimilatory behavior & $\begin{array}{l}\text { Consistently patterns like a [- } \\
\text { ATR] vowel in triggering } \\
\text { [-ATR] forms of harmonizing } \\
\text { affixes. }\end{array}$ & $\begin{array}{l}\text { Consistently patterns like a } \\
{[+\mathrm{ATR}] \text { vowel in triggering }} \\
\text { [+ATR] forms of harmonizing } \\
\text { affixes. }\end{array}$ \\
\hline
\end{tabular}

Nothing about the behavior of low vowels as summarized in (19) is in any way surprising; such patterns are fully consistent with the expectations of most existing theoretical approaches to [ATR] phenomena, under which marked patterning of low [+ATR] vowels and unmarked patterning of low [-ATR] vowels is widely taken for granted (see for example Archangeli \& Pulleyblank 1994, Cahill 2007, Calabrese 1995, Leitch 1996) as being the expected norm not only in /2IU/ ATR harmony languages but in /1IU/ languages as well.

Surprisingly, however, there is evidence that the patterning of low vowels in /1IU/ systems departs in several respects from the expected picture in (19). One difference concerns the level of attestation of low [+ATR] vowels. While clear cases of /2IU/ languages in which such a vowel occurs, either as a contrastive phoneme (as in Degema) or a conditioned allophone of /a/ (as in Kinande) are well-enough attested, fully unambiguous cases of /1IU/ languages in which a vowel [a] occurs at all are quite rare at best.

To begin with, allophonic low [+ATR] vowels are not clearly attested in /1IU/ systems at all. (No examples are found in Casali 2003, nor are any such cases presently known to me.) Such a finding is arguably reflective of the broader generalization that spreading of [+ATR] is not characteristic of /1IU/ systems. Perhaps more surprisingly, however, fully unambiguous cases of

Vata (Kaye 1982) and Wala (Kleinewillingöfer 1990).

20 The qualification "regularly" is needed here because we do find a few /2IU/ languages, e.g., Luo (Swenson 2015) and Turkana (Noske 1996) in which most roots with /a/ take [-ATR] allomorphs of harmonizing affixes, while a few /a/ roots exceptionally condition [+ATR] allomorphs. Such roots may be historical reflexes of a low [+ATR] (phonemic) vowel that was present in an earlier stage of language development. In some phonological frameworks, it might be possible to analyse the roots in question as containing an underlying low [+ATR] vowel synchronically as well, with the underlying contrast between the [+ATR] and [-ATR] low vowels being neutralized on the surface. 
/1IU/ languages with a genuinely low [+ATR] phonemic vowel are not strongly attested either. Because this is a strong claim, and one that may well strike the reader as implausible, it will be worth looking at it in some detail.

Certainly, there are /1IU/ languages which have been analyzed as having a contrastive low [+ATR] vowel. In all likelihood, the best known such case is Wolof. Wolof has a non-high central vowel, symbolized [ə] in most accounts, that functions harmonically as the [+ATR] counterpart of /a/. At least two detailed analyses of the Wolof harmony patterns, treat the vowel [ə] as a [+low], [+ATR] vowel (Archangeli \& Pulleyblank 1994 and Pulleyblank 1996). However, while the harmonic patterning of /a/ makes this analysis an attractive one (since alternations involving [ə] and [a] involve, under this analysis, just a single featural change, to a vowel's [ATR] value), it is not clear that the eighth vowel [ə] in Wolof is in fact phonetically low rather than mid. The original source on Wolof on which most subsequent analyses have been based, Ka (1987), is arguably more suggestive of a /i e $\varepsilon$ a $ә \rho \mathrm{o} \mathrm{u} /$ system, where /ə/ is a mid central [+ATR] vowel.

Various other /1IU/ languages also have a non-high central vowel, generally transcribed [ə], that contrasts with [a]. Such systems include Akoose (Hedinger \& Hedinger 1977), the Anglo and Tongu dialects of Ewe (Mensah 1977), Attie (Kutsch Lojenga \& Hood 1982), Bini (Wescott 1962), Ewondo (Hartell 1993), Kwanja (Blench 1993), Mabaan (Andersen 1999), Mono (Olson 2005), Nizaa (Blench 1993), Omotik (Rottland 1980) and Seme (Marchese 1983). However, in none of these cases is it entirely clear that the relevant vowel is low and not mid, and in many of them there are fairly clear indications that it is not phonetically low. ${ }^{21}$

Similar empirical challenges potentially arise, of course, in connection with the interpretation of non-high central [+ATR] vowels in /2IU/ languages; it is not always easy to tell from a descriptive source whether such vowel is a phonetically low or mid vowel. Descriptions are not always very clear and detailed on this point, and even if a "///" vowel is shown as mid or low in a vowel chart, one might be tempted to wonder, in the absence of detailed discussion of the issue, how clearly the matter has been resolved and on what basis. Nevertheless, we find at least a reasonable number of /2IU/ languages in which it is possible to be fairly confident that such a [+ATR] counterpart of /a/ is in fact a low vowel, either because formant measurements clearly warrant such a conclusion (as in Akposso; Starwalt 2008, Degema; Fulop et. al. 1998, Igede; Armstrong 1985:104, Lango; Noonan 1992 and Kasem; Adongo 1976) or because such a conclusion is at least strongly supported by very clear impressionistic phonetic reports (as in Crouch \& Herbert's (2003) description of Deg or Local \& Lodge's (1996) description of Kalenjin).

Interestingly, and perhaps importantly, it does not seem to matter very much in /2IU/ systems whether a non-high vowel functioning as the [+ATR] counterpart of [a] in a /2IU/ system is low or mid, at least as far as markedness is concerned. In either case, such vowels typically pattern as marked relative to the [-ATR] vowel [a], e.g., in having a restricted distribution and/or low frequency of occurrence. I am not aware of any /2IU/ languages in which it might be tempting to

21 Likpe (Sekpele), a Kwa language spoken in in Eastern Ghana represents a further potential case that at first inspection seems quite promising, as an acoustic study by Lomotey (2009) strongly suggests a system of eight contrastive oral vowels /i e $\varepsilon$ a $\supset$ o u/ in which the "eighth" vowel (here represented, following most descriptions as / $/$ /) as a low, rather than a mid, central vowel. This case is not necessarily as fully conclusive as might be supposed, however, both because of competing claims (Delalorm 2009) to the effect that the language is actually a ten vowel / i i e $\varepsilon$ a $ว \supset$ o $\mho \mathrm{u} /$ and for other reasons discussed in Casali (2014). 
regard a non-high (whether low or mid) central [+ATR] vowel as an unmarked sound. ${ }^{22}$ (cf. Akposso (Anderson 1999), Bongo (Kilpatrick 1985), Koromfe (Rennison 1984, 1986), Lango (Noonan 1992) and Moro (Andersen 1986)). And, of course, we have seen that non-central mid [+ATR] vowels [e], [o] also pattern as characteristically marked in /2IU/ systems. Thus, the overall descriptive generalization appears to be very simple: non-high [+ATR] vowels in /2IU/ systems are marked.

The finding that low and mid vowels pattern alike with respect to markedness raises the natural possibility that the same might be the case in /1IU/ systems as well. If so, then it should not matter much in a /1IU/ language, as it seems not to in /2IU/ languages (as far as markedness status is concerned), whether a non-high central vowel functioning as a [+ATR] counterpart of $/ \mathrm{a} /$ is low or mid. Plausibly, we might expect non-high central [+ATR] vowels, whether or low or mid, to pattern alike with respect to markedness in /1IU/ systems. In this case, the quantity of relevant evidence to consider increases significantly. For while /1IU/ languages with a clearly low [+ATR] central vowel are rare, /1IU/ languages with a non-high [+ATR] central vowel (whether clearly mid or ambiguously low / mid) are well attested, as noted above. It thus becomes worth asking whether such vowels characteristically pattern as marked sounds (as they clearly do in /2IU/ systems) or as unmarked ones.

Though the question clearly warrants more extensive investigation, there seems to be very little clear evidence that non-high central [+ATR] vowels, whether mid or (potentially) low, characteristically behave as marked segments in $/ 1 \mathrm{IU} /$ systems. ${ }^{23}$ In fact, there is at least some weakly suggestive evidence to the contrary, in that low/mid central vowels in /1IU/ systems sometimes occur with high frequency and/or have wide distributions.

According to Mensah (1977), the vowel /o/ (analyzed as a low advanced vowel functioning as the harmonic counterpart of /a/ in Clements 1974) is the most frequently occurring vowel in the Anlo and Tongu dialects of Ewe. In Mono, a Ubangi language with a /i e a $ə$ i 0 o u/ system, the vowel /a/ is treated by Olson (2005) as having the same height features as /e/, /o/. Although Mono does not have a productive tongue root harmony system and lacks a front retracted vowel $/ \varepsilon /$, it nevertheless qualifies as a /1IU/ system (in view of the /o/ - /0/ contrast in back vowels) in our terms. The vowel $/ \mathrm{a} /$ is the most frequently occurring vowel $(/ \mathrm{a} /$ is second) in text material and is particularly common in function words. For Likpe, a language that has generally been described as having an eight-vowel /i e $\varepsilon$ a $ว$ o u u/ system (Ameka 2009, Lomotey 2009, Ring 2003), ${ }^{24}$ Ring (2003: 19) notes that /a/, /a/ and /o/ are the three most common vowels in roots. /a/ is also the most

22 /2IU/ languages in which a phonemic low or mid [+ATR] vowel is specifically cited as occurring with low overall frequency and/or being distributionally restricted in some way include Akposso (Anderson 1999), Bongo (Kilpatrick 1985), Koromfe (Rennison 1984, 1986), Lango (Noonan 1992) and Moro (Andersen 1986).

23 Archangeli \& Pulleyblank (1994:225-239) note that the non-high vowel [ə] which functions as the [+ATR] counterpart of [a] in Wolof cannot occur as a long vowel: [a] can occur both with and without contrastive length whereas [ə] is always short. While this might perhaps be taken as a markedness avoidance, the pattern does not necessarily lend itself straightforwardly to analysis as classical positional neutralization effect. A lengthened syllable nucleus is not generally considered to be a weak prosodic position, in which marked sounds might be expected to be avoided, but rather a strong one. This suggests that the absence of [ə] is not simple markedness avoidance and that the explanation for the gap may lay elsewhere. I am not aware of any other evidence that would diagnose [ə] as a marked sound in Wolof. ten-vowel /i r e $\varepsilon$ a $ә$ о $~ \mho \mathrm{u} /$, by Delalorm (2009) (see Casali (2014) for more detailed discussion). 
frequent vowel found in pronouns, occurring in three out of six paradigmatic forms. A description of Likpe verb extensions also suggests that / / / is a common and widely distributed vowel in the language (Ameka 2009).

Finally, there is evidence that low vowels in /1IU/ languages differ in the range of assimilatory patterns they give rise to. As noted above, the generalization that a low and phonetically retracted root vowel /a/ conditions [-ATR], and not [+ATR], allomorphs of harmonizing affixes holds consistently of /2IU/ languages. This is not always the case, however, in /1IU/ systems. In a number of /1IU/ languages, including Bhele (Kutsch Lojenga 1994a), Mokpwe (Henson n.d.), Nata (Gambarage, to appear), Komo (Thomas 1992) and nearly all Bantu C languages, the low vowel /a/, in its occurrence as a root vowel, fails to condition [-ATR] allomorphs of harmonizing affixes, but takes [+ATR] allomorphs instead, as illustrated in the Ntomba examples below, drawn from Leitch (1996: 51; the original source is Mamet 1955). Examples (20a-d) illustrate the normal harmonizing behavior of two mid vowel affixes with roots containing non-low vowels: a wordinitial noun class prefix $[\mathrm{e}] \sim[\varepsilon]$ and an applicative suffix $[\mathrm{el}] \sim[\varepsilon \mathrm{el}] \sim[\mathrm{en}]$. Example $(20 \mathrm{e})$ shows that the same mid vowel affixes surface disharmonically with a [+ATR] form [e] or [o] when the root vowel is [a]. (Note that the word-final [o] is a nominalizing suffix that is not subject to harmony.)
a. $\varepsilon-l o k-\varepsilon l-o$
'ensorcellement'
b. e-bót-el-o
'gestation
c. $\varepsilon-k \varepsilon ́ n d-\varepsilon 1-\mathrm{o}$
'marche'
d. e-kih-el-o
'siege'
e. e-kan-en-o
'pensee'

Moreover, in many of the Bantu C languages that display this pattern (Leitch 1996: 174), the vowel [a] is able to freely co-occur root-internally with both high and mid [+ATR] vowels but not with [-ATR] vowels $[\varepsilon]$, [o]. In essence, the single low vowel /a/, though phonetically retracted in such languages, shows greater harmonic affinity with the [+ATR] than the [-ATR] non-low vowels, and could almost be treated, as far as its phonological patterning (though not its phonetic quality) is concerned, as a [+ATR] vowel.

The type of pattern in (20), in which a low vowel [a] conditions [+ATR] allomorphs of harmonizing affixes with mid vowels, is by no means universal in /1IU/ languages. In some (and likely many) /1IU/ languages, a root vowel [a] triggers [-ATR] allomorphs of harmonizing affixes. Yoruba (Archangeli \& Pulleyblank 1989, Przezdziecki 2005) is a well-known case of this type. It is thus clear that /1IU/ languages can give rise to two low vowel harmony patterns: one in which a root vowel [a] conditions [-ATR] allomorphs of harmonizing affixes, as in Yoruba, and another in which it conditions [+ATR] allomorphs of harmonizing affixes, as in Bantu C. In contrast, only the former pattern is clearly attested in /2IU/ languages.

If it should hold up, the generalization that the Bantu $C$ low vowel pattern is found in $/ 1 \mathrm{IU} / \mathrm{but}$ not /2IU/ systems is unexpected. It is important to recall that the only basic difference between the two systems is a difference in high vowels: /2IU/ systems must have two contrasting sets of high vowels, while /1IU/ systems must have just a single set of phonemic high vowels. It is certainly not immediately obvious why such a difference should correlate with any significant differences in the patterning of low vowels in the two systems. In fact, many (indeed, most) /2IU/ languages have exactly the same inventory of non-high vowels ([e], [o], [c], [o], [a]) found in both Bantu $\mathrm{C}$ 
and Yoruba (and the vast majority of other /1IU/ languages). The problem of understanding why the two inventory types should give rise to different ranges of variation in low vowel behavior is thus an important one.

\section{Summary and implications}

This paper has presented evidence of a number of ways in which /1IU/ and /2IU/ vowel systems differ in their characteristic assimilatory and markedness-related patterns involving tongue root features. At a relatively specific level, the differences can be summarized as follows:

1. Assimilatory dominance of [+ATR] vowels is highly typical of /2IU/, whereas [-ATR] dominance is more characteristic of /1IU/ systems.

2. Root internal co-occurrence of high [+ATR] vowels [i], [u] and mid [-ATR] vowels $[\varepsilon],[0]$ is typical of /1IU/ but not /2IU/ systems.

3. Positional neutralization of tongue root contrasts at all tongue heights to [-ATR] quality is quite common in $/ 2 \mathrm{IU} /$, but not /1IU/ systems. Many /2IU/ languages show distributional patterns in which only the five [-ATR] vowels $[\mathrm{I}],[\mho],[\varepsilon],[0],[\mathrm{a}]$ are permitted, to the exclusion of any [+ATR] vowels, in some non-assimilatory context(s), e.g., some class(es) of function words. Positional neutralization of [ATR] contrasts, in either high or non-high vowels, to [+ATR] is not characteristic of /2IU/ languages. /1IU/ languages show evidence of treating [-ATR] as the marked value in both high and mid vowels. The high [-ATR] vowels [I], [च] are entirely avoided in most /1IU/ languages, so that high vowels are consistently [+ATR] [i], [u]. Mid [-ATR] vowels [ $\varepsilon]$, [0], though contrastive in /1IU/ languages, sometimes have a restricted distribution relative to their [+ATR] counterparts [e], [o]. Thus, whereas /2IU/ languages treat non-low $[\mathrm{i}],[\mathrm{u}],[\mathrm{e}],[\mathrm{o}]$ as marked relative to $[\mathrm{I}],[\mathrm{J}],[\varepsilon],[\mathrm{o}]$, the opposite asymmetry appears to be more characteristic of /1IU/ languages.

4. In /2IU/ languages, low and phonetically tongue-root-advanced vowels are clearly attested, both as contrastive phonemes (e.g., in Degema) and as conditioned allophonic variants of $/ \mathrm{a} / \mathrm{in}$ [+ATR] contexts (e.g., in Akan). Unambiguous cases of /1IU/ languages in which such a vowel occurs at all, either contrastively or allophonically, are not very clearly attested as far as can be determined at present.

5. In /2IU/ languages, non-high central (and non-central) [+ATR] vowels, whether low, mid or ambiguously low/mid, typically behave like marked sounds with respect to frequency and distribution. In /1IU/ languages, there is little evidence at present that non-high central (and non-central) [+ATR] vowels (which are in all known cases at least arguably non-low, as noted under 4 above) pattern like marked sounds, and there is a certain amount of evidence that points at least weakly toward the opposite conclusion, i.e., there are /1IU/ languages in which a [+ATR] [ə]-like vowel occurs with high frequency and/or very wide distribution.

6. In /2IU/ languages, a low [-ATR] root vowel /a/ consistently conditions [-ATR] allomorphs of harmonizing affixes. While there are no known /2IU/ languages that are exceptions to this generalization, a number of /1IU/ languages (for example, those of Bantu Zone C) clearly manifest a different pattern in which the vowel /a/ in a root morpheme triggers the [+ATR] form of a harmonizing affix. 
Intuitively, it is very tempting to suspect that the generalizations listed atomistically above are somehow connected, and reflective of a more fundamental reality. It seems unlikely to be coincidental that the same set of vowels (i.e., the [+ATR] vowels [i], [u], [e], [o], [a]) that is characteristically dominant in /2IU/ languages is also commonly subject to distributional restrictions. Nor does it seem plausible that dominance of [-ATR] in /1IU/ systems is unrelated to marked patterning of non-low [-ATR] vowels in the same systems. Such a connection is exactly what might be expected, for example, under a traditional understanding of markedness in which assimilation is expected to be to the marked value of a feature (see Causley 1999, de Lacy 2006, Rice 2007 for some discussion). Indeed, as far as non-low vowels are concerned, it would be possible to describe the system-related differences succinctly by saying that $[+$ ATR] is the marked (and dominant) value in /2IU/ systems, while [-ATR] is marked (and dominant) in /1IU/ systems. The same generalization extends unproblematically to low vowels in /2IU/ systems, for which [+ATR] is both the marked and dominant value. It is true that the behavior of low vowels in /1IU/ systems challenges this simple picture, in that there is little evidence that that vowel /a/ behaves like a marked vowel (as its non-low [-ATR] counterparts do) in /1IU/ systems. However, while low vowel patterning in the two systems does not immediately suggest a clear difference in marked [ATR] value, there is nevertheless evidence of inventory-related differences (Generalizations 4-6 above) in the patterning of low vowels as well. Without a closer look than can be afforded here, it is difficult to assess the degree to which these might be reasonably analyzed as reflecting a difference in a system's marked [ATR] value, as seems intuitively attractive in the case of non-low vowels. There, are, however, some differences that at least suggest that the matter needs further attention. (See Casali, in preparation, for more detailed discussion.)

The typological generalizations described here have important implications for both phonological theory and descriptive practice. With respect to practice, they can serve as a guide to further research on tongue root harmony languages by suggesting questions that are worth investigating in descriptive fieldwork. Here I adopt the position, which is articulated in work such as Dixon (2010) and would, I think, be quite widely accepted, that there should be a natural feedback relationship between, on the one hand, established typological generalizations and theories intended to account for them and, on the other hand, grammatical and phonological descriptions of individual languages. It is essential, of course, that theoretical and typological work be informed by accurate descriptions of particular languages. However, information flow must work in the opposite direction as well. Descriptive work on a language can be more effectively focused if it is informed by a relatively accurate and complete typological picture gained from previous study of other languages. Such an understanding of typology can suggest important research questions to be investigated in the course of work on additional languages.

To take a concrete example, the finding that many /2IU/ languages restrict the occurrence of [+ATR] vowels in various grammatical word contexts suggests that the distribution of vowel classes in function words such as pronouns and determiners is a topic worth investigating in a tongue root harmony language. If the trends evident in Section 5.1 hold up generally, it is likely that study of additional /2IU/ languages may reveal pronominal systems with only [-ATR] vowels (at least outside contexts where harmony is at work). While the degree to this expectation is borne out remains to be seen, the important point here is simply that it is a question worth investigating in the course of fieldwork on a tongue root harmony language. For /1IU/ languages as well, the same question is worth investigating: do we find that the full set of phonemic vowels occurs in 
closed function word classes such as pronouns, or are the vowels found in some such contexts limited to a subset of the language's full vowel system? And where the latter occurs, which vowels are permitted in the contexts that show restrictions? These are questions which have often not been directly treated in descriptions of ATR harmony systems, but there is reason to believe that they are significant ones.

As a second example, even a topic as seemingly uninteresting as the question of whether roots with just a low vowel [a] trigger [-ATR] or [+ATR] allomorphs of harmonizing affixes takes on greater potential interest in light of the fact that the most naturally expected answer (i.e., the former pattern) does not turn out to hold in all harmony languages. That is, we find a fair number of /1IU/ languages in which a root vowel [a] conditions [+ATR] allomorphs of harmonizing affixes with mid vowels, as discussed in Section 6 above. Because such languages go against the most natural expectation in this regard (i.e., that the root vowel [a] should take [-ATR] forms of alternating affixes), the outcome of the matter cannot simply be taken for granted for descriptive purposes in other languages, but is worth clearly addressing in a description.

Of course, the findings presented here furnish no clear evidence that the less expected possibility (i.e., that [a] should take [+ATR] allomorphs of harmonizing affixes) occurs in /2IU/ languages as well; in fact, it has been suggested as a typological hypothesis (Generalization 6 above) that this is not the case. This does not mean, however, that the question does not need to be directly investigated in /2IU/ systems as well. The correctness of the research hypothesis cannot simply be taken for granted, nor does its value lie in the certain knowledge that it must be correct. Rather, it is important that it be investigated empirically in both /1IU/ and /2IU/ languages, so as to lead to a clearer and more reliable overall picture of the degree to which the two types of systems do or do not differ in this particular respect. It would be helpful in any description of a tongue root harmony language of either inventory type to explicitly describe and illustrate the affix harmony triggered by /a/ roots. It cannot simply be taken for granted that because /a/ is phonetically retracted it will condition [-ATR] forms of harmonizing affixes.

With respect to other specific issues as well, similar considerations apply. The point is not that the typological generalizations suggested by the body of research presented here are guaranteed to be borne out in further languages that are investigated. On the contrary, it is entirely possible that they may need to be modified in various respects. What is important, however, is that the typological picture that has emerged is clear enough, and finds sufficient initial support, to yield expectations to guide field research.

The same typological picture has significant implications for phonological theory as well. Specifically, it poses a potentially difficult explanatory challenge: we would like to know why /1IU/ and /2IU/ systems behave differently in the ways that they do. While there is room for questioning whether some of the system-related behavioral differences will ultimately prove to reflect absolute universals or merely statistical tendencies, it seems abundantly clear that the two systems show a number of different characteristic tendencies, which must be explained. This is true irrespective of whether one assumes that the differences are better accounted for in terms of some set of innate cognitive principles specific to language ("universal grammar"), general cognitive principles that are not strictly language-specific, or external factors such as natural pathways of diachronic change (Blevins 2004, 2006).

There is also a potentially encouraging side to the typological generalizations presented in this paper. The discovery of additional inventory-related differences in phonological patterning, beyond the assimilatory differences revealed by earlier work such as Casali (2003), makes it 
possible to work with a more complete picture. That is, one might optimistically hope that the additional behavioral differences revealed in the present study could shed additional light on a potentially difficult problem and that the task of understanding why the inventories behave differently should be easier with a fuller view of the nature of the problem. If nothing else, it is clear that differences in the dominant [ATR] value are not the only thing that must be explained; there are apparent differences in markedness relations and low vowel patterning that must be accounted for as well. A plausible possibility to entertain (though its correctness is not necessarily guaranteed) is that the assimilatory and other differences are related.

In fact, there is a natural explanatory approach to forging an essential connection between assimilatory dominance and distributional markedness, familiar from much theoretical work in pre-OT frameworks (e.g., Archangeli \& Pulleyblank 1989, Cahill 1996, Kiparsky 1985, Ringen 1975, Snider 1989b, Steriade 1995, Thomas 1992) but also from various OT studies (e.g., Akinlabi 1997, Cahill 2007, Casali 2003, Causley 1999, Leitch 1996). This approach is a representational one, in which tongue root contrasts are assumed to be privatively encoded as a distinction between present and absent feature values: the markedness and dominance of a particular tongue root quality are taken to be indicative of representational presence of the corresponding tongue root feature value, with the opposite (unmarked and recessive) quality being representationally absent. While the task of developing such a model in detail is beyond the scope of this paper (see Casali, in preparation, for fuller treatment), it is not difficult to describe the general essence of such an approach in broad terms.

We might assume, to begin with, that /2IU/ languages, in which " $[+\mathrm{ATR}]$ " quality is characteristically both marked and dominant, employ a privative feature [ATR] (specified on tongue-root-advanced vowels [i], [u], [e], [o], [a] ]), while "[-ATR]" quality has no direct representational presence, being encoded simply as the absence of any tongue root feature. Being visible to constraints (or, in a rule-based framework, rules) that can compel its preservation in assimilatory contexts, privative [ATR] is expected, all else equal, to be dominant in assimilation processes. In a model employing a constraint MAX(ATR) or some close equivalent, for example, one would suppose that the assimilation of advanced vowels to retracted vowels, but not assimilation of the latter (which bear no tongue root feature) to the former, violates such a constraint. In this way, a potential bias toward the assimilation patterns of the latter type is established. (See Casali 2003, Causley 1999 for relevant discussion.) Note that even if a corresponding constraint MAX(RTR) is assumed to exist (as will indeed be suggested below), such a constraint will be of no effect in a language in which no feature [RTR] is employed, and in which retracted tongue root quality is represented simply as the absence of any tongue root feature. Thus, a change in an [ATR]-based /2IU/ language from advanced to retracted quality violates $\operatorname{MAX}(\mathrm{ATR})$, while a change from retracted to advanced quality violates neither MAX(ATR) nor MAX(RTR). The latter type of change is therefore more optimal in cases where assimilation is forced by some harmony constraint.

At the same time, specified [ATR] values can also be assumed to be visible to markedness constraints which, depending on their ranking, might effectively restrict the distribution of vowels that bear such specifications. If we adopt a model in which markedness constraints on tongue root quality are formulated as literal bans on specified tongue root features, either in absolute terms (e.g., a constraint $*[A T R]$ ) or in combination with other feature values (e.g., a constraint *[low, ATR]), then we expect that only vowels that are specified for a tongue root feature can violate markedness constraints. Hence, only such vowels are expected to show marked patterning. In this 
way, we might account for the finding (see Section 5.1 above), which is surprising on substantive grounds, that high retracted vowels overwhelmingly pattern as unmarked sounds in /2IU/ languages. Such unmarked patterning is, under the account proposed here, a consequence of representational, rather than strictly substantive, factors. Regardless of their phonetic properties (which are widely assumed to be functionally problematic), the vowels [I], [ $\mathrm{J}$ ] will be representationally unspecified for any tongue root feature in an [ATR]-based /2IU/ language, and hence necessarily unmarked.

For /1IU/ languages, we might adopt, as a starting point, the assumption that tongue root contrasts are based on a different specified privative feature, which we might take as a feature [RTR] (= Retracted Tongue Root), following various previous studies (e.g., Leitch 1996). [RTR] would, under this approach, be present on retracted vowels $[\varepsilon]$, [०], but absent on advanced vowels [i], [u], [e], [o]. Such an assumption, in conjunction with assumptions (which are fully analogous to those sketched above for [ATR]-based systems) about visibility of specified [RTR] values to relevant constraints (e.g., MAX(RTR)), would lead us to expect, all else equal, assimilatory dominance of retracted vowels $/ \varepsilon /, / \mathrm{J}$ in such languages, in good agreement with what we actually find. We might also expect to find unmarked patterning of advanced vowels, [i], [u], [e], [o], which is also in good agreement with what we appear to find. Non-trivial questions and problems arise in extending such an account to low vowels. For example, there is a question of whether the low vowel [a], for which tongue root position is non-contrastive in (all known) /1IU/ systems, should bear a redundant [RTR] specification or not (see Leitch 1996). However, the hypothesis that /1IU/ systems employ a different active tongue root feature than /2IU/ systems at least provides a potential basis for making initial sense of the differences we find in the patterning of the two systems (Casali 1996, 2003, Causley 1999, Leitch 1996, Steriade 1995).

Many potentially challenging questions arise in connection with a research program that attempts to understand the differences we observe in the characteristic patterning of /1IU/ and /2IU/ systems in terms of a different specified tongue root feature ([RTR] in the former, [ATR] in the latter). In addition to the very obvious and important (and seemingly quite difficult) question of why the two systems should employ different (see Casali 2008: 527 and references there for some discussion), there are various specific technical and conceptual issues that arise in following such an approach as well. Whether or not an account these general lines, or some other, and perhaps quite different approach, should eventually prove superior, it is clear that the task of understanding the basis for the differences in characteristic patterning of /1IU/ and /2IU/ systems represents an interesting and important problem for phonological theory. 


\section{References}

Abaglo, Poovi \& Diana Archangeli. 1989. Language particular underspecification: Gengbe /e/ and Yoruba /i/. Linguistic Inquiry 20. 457-480.

Adive, John Raji. 1989. The verbal piece in Ebira. Dallas, TX: SIL \& University of Texas at Arlington.

Adjekum, Grace, Mary E. Holman \& Thomas W. Holman. 1993. Phonological processes in Anuf . (Language Monographs, 2.) Legon, Ghana: Institute of African Studies, University of Ghana.

Adongo, S. T. 1976. Vowel Harmony in Kasem. Legon, Ghana: University of Ghana unpublished MS.

Akinlabi, Akinbiyi. 1997. Kalabari vowel harmony. The Linguistic Review 14. 97-138.

Allen, Blake, Douglas Pulleyblank \& Oládiípò Ajibóyè. 2013. Articulatory mapping of Yoruba vowels: An ultrasound study. Phonology 30. 183-210.

Ameka, Felix K. 2009. Verb extensions in Likpe (Sekpele). Journal of West African Languages 36(1-2). 139-157.

Andersen, Torben. 1986. Tone splitting and vowel quality: Evidence from Lugbara. Studies in African Linguistics 17. 55-68.

Andersen, Torben. 1987. An outline of Lulubo phonology. Studies in African Linguistics 18. 3965.

Andersen, Torben. 1989. The Päri vowel systems with an internal reconstruction of its historical development. Journal of African Languages and Linguistics 11. 1-20.

Andersen, Torben. 1999. Vowel harmony and vowel alternation in Mayak (Western Nilotic). Studies in African Linguistics 28. 1-29.

Andersen, Torben. 2004. Jumjum phonology. Studies in African Linguistics 33. 133-162.

Anderson, Coleen G. 1999. ATR vowel harmony in Akposso. Studies in African Linguistics 28. 186-214.

Archangeli, Diana \& Douglas Pulleyblank. 1989. Yoruba vowel harmony. Linguistic Inquiry 20. 173-217.

Archangeli, Diana, \& Douglas Pulleyblank. 1994. Grounded phonology. (Current Studies in Linguistics, 25.) Cambridge, MA: MIT Press.

Archangeli, Diana, \& Douglas Pulleyblank. 2002. Kinande vowel harmony: domains, grounded conditions and one sided alignment. Phonology 19. 139-188.

Armstrong, Robert G. 1985. The tenth vowel in proto-Kwa. Journal of West African Languages 15(1). 104-110.

Awobuluyi, Oladele. The morphophonemics of Owon Afa. Research Notes from the Department of Linguistics and Nigerian Languages, University of Ibadan 5(2). 25-44.

Bakovic, Eric. 2000. Harmony, dominance and control. New Brunswick, NJ: Rutgers University Ph.D. dissertation. http://roa.rutgers.edu/files/360-1199/roa-360-bakovic-2.pdf.

Bakovic, Eric \& Colin Wilson. 2000. Transparency, locality, and targeted constraints. San Diego, CA \& Los Angeles, CA: University of California, San Diego and University of California, Los Angeles unpublished MS. http://roa.rutgers.edu/files/430-1200/roa-437-bakovic-1.pdf. 
Beckman, Jill N. 1997. Postional faithfulness, positional neutralisation and Shona vowel harmony. Phonology 14. 1-46.

Bergman, Richard. 1971. Vowel sandhi and word division in Igede. Journal of West African Languages 8(1). 13-25.

Berry, J. 1955. Some notes on the phonology of the Nzema and Ahanta dialects. Bulletin of the School of Oriental and African Studies 17. 160-165.

Blench, Roger. 1993. An outline classification of the Mambiloid languages. Journal of West African Languages 23(1). 105-118.

Blevins, Juliette. 2004. Evolutionary phonology. Cambridge: Cambridge University Press.

Blevins, Juliette. 2006. A theoretical synopsis of Evolutionary Phonology. Theoretical Linguistics 32(2). 117-166.

Bole-Richard, Rémy. 1981. Une autre approche de l'harmonie vocalique: le mot phonologique en ega. Cahiers Ivoiriens de Recherche Linguistique 10. 31-51. Abidjan: Institut de Linguistique Appliquée, Université Nationale de Côte d'Ivoire.

Bole-Richard, Rémy. 1982. L'ega. In G. Hérault (ed.), Atlas des Langues Kwa de Côte d'Ivoire, vol. 1, 360-401. Abidjan: Université d'Abidjan, Institut de Linguistique Appliquée \& Agence de Coopération Culturelle et Technique.

Boyd, Ginger. 1997. A phonology and grammar of Mbodoms. Arlington, TX : University of Texas at Arlington M.A. thesis.

Boyd, Ginger. 2015. The phonological systems of the Mbam languages of Cameroon with a focus on vowels and vowel harmony. Leiden: University of Leiden Ph.D. dissertation. (Published by LOT publications, Utrecht, 2015. http://www.lotpublications.nl/the-phonological-systems-ofthe-mbam-languages-of-cameroon-with-a-focus-on-vowels-and-vowel-harmony.)

Boyd, Raymond. 1997. Les harmonies vocaliques du zande. Lingua 101. 1-19.

Burmeister, Jonathan. 1982. L'abouré. In G. Hérault (ed.), Atlas des Langues Kwa de Côte d'Ivoire, vol. 1, 67-81. Abidjan: Université d'Abidjan, Institut de Linguistique Appliquée \& Agence de Coopération Culturelle et Technique.

Burmeister, Jonathan. 1988. Personal pronouns in Anyi and related languages. Journal of West African Languages 18(2). 83-104.

Cahill, Michael. 1996. ATR harmony in Konni. Ohio State University Working Papers in Linguistics 48. 13-30.

Cahill, Michael. 2007. Aspects of the Morphology and Phonology of Konni. Dallas, TX: SIL.

Calabrese, Andrea. 1995. A constraint-based theory of phonological markedness and simplification procedures. Linguistic Inquiry 26. 373-463.

Calabrese, Andrea. 2005. Markedness and economy in a derivational model of phonology. (Studies in Generative Grammar, 80.) Berlin \& New York: Mouton de Gruyter.

Casali, Roderic F. 1993. On some uses of ATR. Los Angeles, CA: Univerisity of California, Los Angeles unpublished MS.

Casali, Roderic F. 1995a. On the reduction of vowel systems in Volta-Congo. African Languages and Cultures 8(2). 109-121.

Casali, Roderic F. 1995b. Nawuri phonology. (Language Monographs, 3.) Legon, Ghana: Institute of African Studies, University of Ghana.

Casali, Roderic F. 1996. Resolving hiatus. Los Angeles, CA: University of California, Los Angeles Ph.D. dissertation. (Published by Garland Publishing, New York, 1998.)

Casali, Roderic F. 1998. Predicting ATR activity. Chicago Linguistic Society 34(1). 55-68. 
Casali, Roderic F. 2002a. Nawuri ATR harmony in typological perspective. Journal of West African Languages 29(1). 3-43.

Casali, Roderic F. 2002b. [-ATR] Dominance in underlying five-height vowel systems. Paper presented at Annual Conference on African Linguistics 33. Ohio University, March 22-24.

Casali, Roderic F. 2003. [ATR] value asymmetries and underlying vowel inventory structure in Niger-Congo and Nilo-Saharan. Linguistic Typology 7. 307-382.

Casali, Roderic F. 2008. ATR harmony in African languages. Language and Linguistics Compass 2. 496-549. http://onlinelibrary.wiley.com/doi/10.1111/j.1749-818X.2008.00064.x/abstract.

Casali, Roderic F. 2012. [+ATR] dominance in Akan. Journal of West African Languages 39(1). 33-59.

Casali, Roderic F. 2014. Assimilation, markedness and inventory structure in tongue root harmony systems. Langley, BC \& Dallas, TX: Trinity Western University \& SIL unpublished MS. http://roa.rutgers.edu/article/view/1319.

Casali, Roderic F. In preparation. Featural markedness in tongue root harmony systems. Langley, BC \& Dallas, TX: Trinity Western University \& SIL unpublished MS.

Causley, Trisha Kathleen. 1999. Complexity and markedness in optimality theory. Toronto, ON: University of Toronto Ph.D. dissertation.

Chumbow, Beban Sammy. 1982a. Ogori vowel harmony: An autosegmental perspective. Linguistic Analysis 10(1). 61-93.

Chumbow, Beban Sammy. 1982b. Contraction and tone polarization in Ogori. Journal of West African Languages 12(1). 89-103.

Clements, G. N. 1974. Vowel harmony in Ewe. Studies in African Linguistics 5. 281-301.

Clements, George N. 1981. Akan vowel harmony: A nonlinear analysis. Harvard Studies in Phonology 2. 108-177.

Clements, George N. 1991. Vowel height assimilation in Bantu languages. Working Papers of the Cornell Phonetics Laboratory 5. 37-76.

Clements, George N. 2000. Phonology. In Bernd Heine \& Derek Nurse (eds.), African Languages: An Introduction, 123-60. Cambridge: Cambridge University Press.

Cohen, Kevin Bretonnel. 2000. Aspects of the grammar of Kukú. München: Lincom Europa.

Crouch, Marjorie \& Patricia Herbert. 2003. Collected field reports on the phonology of Deg. (Collected Language Notes, 24.) Legon, Ghana: Institute of African Studies, University of Ghana.

Dakubu, M. E. Kropp. 1997. Oti-Volta vowel harmony and Dagbani. Gur Papers / Cahiers Voltaïques 2. 81-88.

Dawson, Keith. 1975. L'accord vocalique en tépo. Annales de l'Université d'Abidjan, série H (Linguistique) 8. 15-26.

Delanorm, Cephas. 2009. Vowel harmony in Sekpele. Journal of West African Languages 36(1-2). 201-208.

Delord, J. 1976. Le kabiye. Lomé: Institut National de la Recherche Scientifique.

Dixon, R. M. W. 2010. Basic linguistic theory: Volume 1 methodology. Oxford: Oxford University Press.

Djilla, Mama, Bart Eenkhorn \& Jacqueline Eenkhorn-Pilon. 2004. Phonologie du jôwulu. Köln: Rüdiger Köppe Verlag.

Dolphyne, Florence. 1988. The Akan (Twi-Fante) language: Its sound systems and tonal structure. Accra: Ghana Universities Press. 
Elugbe, Ben Ohi. 1983. The vowels of proto-edoid. Journal of West African Languages 13(1). 7989.

Equipe de la S.I.L. à Guélwongo. 1998. Guide d'orthographe ninkãre. Ouagadougou: Société Internationale de Linguistique.

Fontaney, Louise. 1989. Mboshi: Steps toward a grammar - Part 2. Pholia 4. 71-131. http://www.ddl.ish-lyon.cnrs.fr/Download/Pholia/Pholia_N-4.pdf.

Ford, K.C. 1973. On the loss of cross-height vowel harmony. Research Review, Supplement 4. 5080. Legon, Ghana: University of Ghana, Institute of African Studies.

Fulop, Sean, Ethelbert Kari \& Peter Ladefoged. 1998. An acoustic study of the tongue root contrast in Degema vowels. Phonetica 55. 80-98.

Gambarage, Joash Johannes. To appear. Tongue root restriction and nominal morphological domains in Nata. To appear in University of British Columbia Working Papers in Linguistics.

George, Isaac. 1973. Vowel harmony: Why so restricted in Yoruba? Research Notes from the Department of Linguistics and Nigerian Languages, University of Ibadan 6. 172-188.

Gick, Bryan, Douglas Pulleyblank, Fiona Campbell \& Ngessimo Mutaka. 2006. Low vowels and transparency in Kinande vowel harmony. Phonology 23. 1-20.

Goad, Heather. 1993. On the configuration of height features. Los Angeles, CA: University of Southern California Ph.D. dissertation.

Guion, Susan G., Mark W. Post \& Doris L. Payne. 2004. Phonetic correlates of tongue root vowel contrasts in Maa. Journal of Phonetics 32. 517-42.

Hamaya, Mitsuyo. 1997. Vowel harmony in Maasai. Eugene, OR: University of Oregon unpublished MS.

Hansford, Keir L. 1988. A phonology and grammar of Chumburung. Dallas, TX: SIL unpublished MS.

Hansford, Keir \& Gillian Hansford. 1989. Borrowed words in Chumburung. African Languages and Cultures 2(1). 39-50.

Harley, Matthew W. 2005. A descriptive grammar of Tuwuli, a Kwa language of Ghana. London: University of London Ph.D. dissertation.

Hartell, Rhonda L, ed. 1993. Alphabets of Africa. Dakar: UNESCO-Dakar Regional Office \& SIL. Hedinger, Robert \& Sylvia Hedinger. 1977. Phonology of Ak se (Bakossi). Yaoundé: SIL.

Henson, Bonnie. n.d. Resolving vowel hiatus in Mòkpwè. Berkeley, CA: University of California, Berkeley unpublished MS.

Hess, Susan. 1992. Assimilatory effects in a vowel harmony system: an acoustic analysis of advanced tongue root in Akan. Journal of Phonetics 20. 475-492.

Higgins, Holly A. 2011. Ikoma vowel harmony: Phonetics and phonology. Langley, BC: Trinity Western University M.A. thesis.

Hume, Elizabeth. 2011. Markedness. In Marc van Oostendorp, Colin J. Ewen, Elizabeth Hume and Keren Rice (eds.), The Blackwell Companion to Phonology, 79-106. Malden, MA \& Oxford: Wiley-Blackwell.

Hyman, Larry M. 1989. Advanced tongue root in Kinande. Berkeley, CA: University of California, Berkeley unpublished MS.

Hyman, Larry. M. 1999. The historical interpretation of vowel harmony in Bantu. In Jean-Marie Hombert \& Larry M. Hyman (eds.), Bantu Historical Linguistics: Theoretical and Empirical Perspectives, 235-95. Stanford, CA: CSLI. 
Hyman, Larry. 2002. Is there a right-to-left bias in vowel harmony? Paper presented at the Ninth International Phonology Meeting. University of Vienna, November 1-3. http://linguistics.berkeley.edu/ hyman/Hyman_Vienna_VH_paper_forma.pdf.

Jacobson, Leon C. 1978. Dho Luo vowel harmony: a phonetic investigation. UCLA Working Papers in Phonetics 43.

Jacobson, Leon C. 1980. Voice-quality harmony in Western Nilotic languages. In Robert M. Vago (ed.), Issues in Vowel Harmony, 183-200. Amsterdam: John Benjamins.

Ka. Omar. 1987. Wolof phonology and morphology: A non-linear approach. Urbana, IL: University of Illiniois Ph.D. dissertation.

Kari, Ethelbert. 2007. Vowel harmony in Degema, Nigeria. African Study Monographs 28(2). 8797.

Kastelein, Bianca. 1994. A phonological and grammatical sketch of DuRop. Leiden: University of Leiden Ph.D. dissertation.

Kaye, Jonathan D. 1981. La sélection des formes pronominales en vata et en d'autres langues kru orientales. Revue Québecoise de Linguistique 11. 117-134.

Kaye, Jonathan D. 1982. Harmony processes in Vata. In Jonathan Kaye, Hilda Koopman \& Dominique Sportiche (eds.), Projet sur les Langues Kru, 60-151. Montreal: University of Quebec at Montreal.

Kidda, Mairo E. 1993. Tangale phonology: A descriptive analysis. Berlin: Dietrich Reimer.

Kingston, John, Neil A. Macmillan, Laura Walsh Dickey, Rachel Thorbum \& Christine Bartels. 1997. Integrality in the perception of tongue root position and voice quality in vowels. Journal of the Acoustical Society of America 101. 1696-1709.

Kilpatrick, Eileen. 1985. Bongo phonology. Occasional Papers in the Study of Sudanese Languages 4. 1-62. Juba: SIL, Institute of Regional Languages \& University of Juba.

Kiparsky, Paul. 1985. Some consequences of Lexical Phonology. Phonology Yearbook 2. 83-138.

Kiparsky, Paul. 2006. The Amphichronic Program vs. Evolutionary Phonology. Theoretical Linguistics 32(2). 217-236.

Kleinewillingöfer, Ulrich. 1990. Aspects of vowel harmony in Waja and Tangale-Waja common vocabulary. Frankfurter Afrikanistische Blätter 2. 93-106.

Kleinewillinghöfer, Ulrich. 1999. The verb in Kusuntu. Paper presented at the 2nd Gur Colloquium. Cotonou, March 29 - April 1.

Kügler, Frank. 2015. Phonological phrasing and ATR vowel harmony in Akan. Phonology 32. 177-204.

Kutsch Lojenga, Constance. 1991. Vowel harmony in Alur: On the crossroads of two systems. In Franz Rottland \& Lucia N. Omondi (eds.), Proceedings of the Third Nilo-Saharan Linguistics Colloquium (Nilo-Saharan, 6), 131-141. Hamburg : H. Buske.

Kutsch Lojenga, Constance. 1994a. The vowel system of BILA, a Bantu language of the northern Bantu borderland in Zaire. Paper presented at the Colloquium on African Languages and Linguistics. University of Leiden.

Kutsch Lojenga, Constance. 1994b. Ngiti: A Central-Sudanic language of Zaire. (Nilo-Saharan, 9.) Köln: Köppe.

Kutsch Lojenga, Constance. 1994c. KiBudu: A Bantu language with nine vowels. Africana Linguistica 11. 127-133. Tervuren: Musée Royal de L'Afrique Centrale.

Kutsch Lojenga, Constance. 1999. In search of the vowel system of LuGungu (Bantu E): Contrast, conditioning, or both? Leiden: University of Leiden Unpublished MS. 
Kutsch Lojenga, Constance. 2008a. Nine vowels and ATR vowel harmony in Lika, a Bantu language in D. R. Congo. Africana Linguistica 14. 63-84.

Kutsch Lojenga, Constance. 2008b. Two types of vowel harmony in Malila (Bantu M.24, Lake Corridor, S.W. Tanzania). Paper presented at the Special World Congress of African Linguistics 6. University of Saõ Paulo, August $11-15$.

Kutsch Lojenga, Constance \& Elizabeth Hood. 1982. L'attie. In G. Hérault (ed.), Atlas des Langues Kwa de Côte d'Ivoire, vol. 1, 227-253. Abidjan: Université d'Abidjan, Institut de Linguistique Appliquée \& Agence de Coopération Culturelle et Technique.

Lacy, Paul de. 2006. Markedness reduction and preservation in phonology. Cambridge: Cambridge University Press.

Laniran, Yetunde O. 1985. Vowel merger and Emalhe vowel harmony. Journal of the Linguistic Association of Nigeria. 3. 3-11.

Lauschitzky, Christiane. 2007. The Verb in Bozo Jenaama. Leiden: University of Leiden M.A. thesis.

Lauschitzky, Christiane. In preparation. A short description of Jenaama phonology. Bamako: SIL unpublished MS.

Leitch, Myles. 1996. Vowel harmonies of the Congo basin: An optimality theory analysis of variation in the Bantu zone C. Vancouver, BC: University of British Columbia Ph.D. dissertation.

Lindau, Mona. 1979. The feature expanded. Journal of Phonetics 7. 163-176.

Lindau, Mona, Leon Jacobson \& Peter Ladefoged. 1972. The feature Advanced Tongue Root. UCLA Working Papers in Phonetics 22. 76-94.

Local, John, and Ken Lodge. 1996. Another travesty of representation: Phonological representation and phonetic interpretation of ATR harmony in Kalenjin. York Papers in Linguistics 17. 77-117.

Lomotey, Charlotte Fofo. 2009. The vowels of the Likpe language. Journal of West African Languages 36(1-2). 209-219.

Mamet, M. 1955. La langue ntomba. Tervuren: Annales du Musée Royale Belge.

Mamet, M. 1960. Le langage des bolia. Tervuren: Annales du Musée Royale Belge.

Marchese, Lynell. 1983. Atlas linguistique kru. Abidjan: Institut de Linguistique Appliquée, Université d'Abidjan \& Agence de Coopération Culturelle et Technique.

Mensah, A. K. 1977. The phonology of the Tongu dialect of Ewe. Legon, Ghana: University of Ghana Graduate Diploma paper.

McCord, Michael Steven. 1989. Acoustical and autosegmental analyses of the Mayogo vowel system. Arlington, TX: University of Texas at Arlington M.A. thesis.

Meier, Paul, Inge Meier \& John Bendor-Samuel. 1975. A grammar of Izi: An Igbo language. Norman, OK: SIL.

Mutaka, Ngessimo. 1995. Vowel harmony in Kinande. Journal of West African Languages 25(2). 41-55.

Noonan, Michael. 1992. A grammar of Lango. Berlin: Mouton de Gruyter.

Noske, Manuela. 1996. [ATR] harmony in Turkana. Studies in African Linguistics 25. 61-99.

Ntumy, Samuel K. 1997. A sketch phonology of the Ahanta language. Tamale, Ghana: Ghana Institute of Linguistics, Literacy and Bible Translation unpublished MS.

Obeng, Samuel Gyasi. 1995. Vowel harmony in Gwa Nmle. Afrikanistische Arbeitspapiere 41. 143-152. 
Obeng, Samuel Gyasi. 2008. Efutu grammar. Muenchen: Lincom Europa.

Odden, David. 1996. The phonology and morphology of Kimatuumbi. Oxford: Clarendon Press.

Olson, Kenneth S. 2005. The phonology of Mono. Dallas, TX: SIL \& University of Texas at Arlington.

Omamor, Augusta Phil. 1973. Uvwiẹ - a case of vowels merging. Research Notes from the Department of Linguistics and Nigerian Languages, University of Ibadan 6. 113-143.

Omamor, Augusta Phil. 1988. Okpe and Uvwie: A case of vowel harmony galore. Journal of West African Languages 18(1). 47-64.

Orie, Olanikẹ Ola. 2003. Two harmony theories and high vowel patterns in Ebira and Yoruba. The Linguistic Review 20. 1-35.

Ourso, Meterwa A. 1989. Phonological processes in the noun class system of Lama. Studies in African Linguistics 20. 151-177.

Oyelaran, Olasope O. 1973. Yoruba vowel co-occurrence restrictions. Studies in African Linguistics 4. 155-182.

Painter, Colin. 1971. Vowel harmony in Anum. Phonetica 23. 239-48.

Painter, Colin. 1972. Phonological features underlying vowel harmony loss in certain West African languages. In Colin Painter, Fourteen Papers on Gwa and Fifty-two Texts in Gwa, 3033. (Collected Language Notes, 12.) Legon, Ghana: Institute of African Studies, University of Ghana.

Painter, Colin. 1973. Cineradiographic data on the feature 'covered' in Twi vowel harmony. Phonetica 28. 97-120.

Paluku, André Mbula. 1998. Description grammatical du kitalinga (Langue Bantu Nord-Est du Zaire). München \& Newcastle: Lincom Europa.

Parkinson, Frederick. 1996. The representation of vowel height in phonology. Columbus, $\mathrm{OH}$ : The Ohio State University Ph.D. dissertation.

Peacock, Wesley. 2007. Collected language notes on the phonology of Nkonya. (Collected Language Notes, 27.) Legon, Ghana: Institute of African Studies, University of Ghana.

Pike, Kenneth L. 1967. Tongue-root position in practical phonetics. Phonetica 17. 129-140.

Plunkett, Gray C. 2006. An overview of the tone system of Foodo and its implications for a standard orthography. Paper presented at the International Workshop on the Description and Documentation of the Ghana-Togo-Mountain Languages. Ho, Ghana, July 24-29.

Przezdziecki, Marek A. 2005. Vowel harmony and coarticulation in three dialects of Yoruba: phonetics determining phonology. Ithaca, NY: Cornell University Ph.D. dissertation.

Pulleyblank, Douglas. 1996. Neutral vowels in Optimality Theory: A comparison of Yoruba and Wolof. Canadian Journal of Linguistics 41. 295-347.

Ravenhill, Judith Timyan. 1982. L'abron. In G. Hérault (ed.), Atlas des Langues Kwa de Côte d'Ivoire, vol. 1, 83-128. Abidjan: Université d'Abidjan, Institut de Linguistique Appliquée \& Agence de Coopération Culturelle et Technique.

Rennison, John. 1984. On the vowel harmonies of Koromfe (Burkina Faso, West Africa). In Wolfgang U. Dressler, Hans C. Luschützky, Oskar E. Pfeiffer \& John R. Rennison (eds.), Phonologica 1984: Proceedings of the Fifth International Phonology Meeting, Eisensdadt, $25-$ 28 June 1984, 239-246. London: Cambridge University Press.

Rennison, John. 1986. On tridirectional feature systems for vowels. In Jacques Durand (ed.), Dependency and Non-linear Phonology, 281-303. London: Croom Helm.

Rennison, John R. 1997. Koromfe. London \& New York: Routledge. 
Rice, Keren. 2007. Markedness in phonology. In Paul de Lacy (ed.), Cambridge Handbook of Phonology, 79-98. Cambridge, UK: Cambridge University Press.

Ring, J. Andrew. 2003. Language structures of Sekpele (Likpe). Tamale, Ghana: Ghana Institute of Linguistics, Literacy and Bible Translation unpublished MS.

Ringen, Catherine O. 1975. Vowel harmony: theoretical implications. Bloomington, IN: Indiana University Ph.D. dissertation. (Published by Garland Publishing, New York, 1988).

Rottland, Franz. 1980. Vowel harmony in Southern Nilotic. Nairobi: University of Nairobi unpublished MS.

Sapir, David J. 1965. A grammar of Diola-Fogny. (West African Language Monographs, 3.) Cambridge: Cambridge University Press.

Sasa, Tomomasa. 2007. A span theoretic account for Kinande dominance and dominance reversal. Paper presented at the 15th Manchester Phonology Meeting. University of Manchester, May 24-26. http://www.englang.ed.ac.uk/mfm/15mfmabbk.pdf

Scholz, Hans-Jurgen. 1976. Igbira phonology. (Language Data Microfiche, African Series, 7.) Huntington Beach, CA: SIL.

Schuh, Russell. 1995. Aspects of Avatime phonology. Studies in African Linguistics 24. 31-67.

Snider, Keith L. 1989a. North Guang Comparative word list: Chumburung, Krachi, Nawuri, Gichode, Gonja. (Comparative African Wordlists, 4.) Legon, Ghana: Institute of African Studies, University of Ghana.

Snider, Keith L. 1989b. Vowel coalescence in Chumburung: An autosegmental analysis. Lingua 78. 217-232.

Snider, Keith L. 1990. Studies in Guang phonology. Leiden: University of Leiden Ph.D. dissertation.

Somé, Pénou-Achille 1982. Systématique du signifiant en dagara variété wulé. Paris: Éditions L'Harmattan \& Agence de Coopération Culturelle et Technique.

Starwalt, Coleen G. A. 2008. The acoustic correlates of ATR harmony in seven- and nine-vowel African languages: A phonetic inquiry into phonological structure. Arlington, TX: University of Texas at Arlington Ph.D. dissertation. http://dspace.uta.edu/handle/10106/1015.

Stegen, Oliver. 2000. Rangi vowel system: Five or seven? Paper presented the Colloquium on African Languages and Linguistics 30. University of Leiden, August 28-30.

Steriade, Donca. 1995. Underspecification and markedness. In John Goldsmith (ed.), Handbook of Phonological Theory, 114-174. Oxford: Basil Blackwell.

Stewart, John M. 1967. Tongue root position in Akan vowel harmony. Phonetica 16. 185-204.

Stewart, John M. 1970. Tongue root position in the Volta-Comoe languages and its significance for the reconstruction of the original Bantu vowel sounds. African Language Studies 11. 34050.

Swenson, Janel. 2015. ATR quality in the Luo vowel system. CanIL Electronic Working Papers 1. 101-145. http://www.canil.ca/joomla/index.php/resources/electronic-working-papers/ewpvolume-1.

Suggett, Colin. 2005. A phonology sketch of Tchourama (Turka). Ouagadougou: SIL unpublished MS.

Tabb, Waller C. 2001. LuBwisi phonology survey. Dallas, TX: SIL unpublished MS.

Tchagbalé, Zakari. 1976. Phonologie et tonologie du tem. Paris: Université de la Sorbonne Nouvelle Ph.D. dissertation. 
Thomas, John Paul. 1992. A morphophonology of Komo: Non-tonal phonology. Grand Forks, ND: University of North Dakota M.A. thesis.

Tiede, Mark K. 1996. An MRI-based study of pharyngeal volume contrasts in Akan and English. Journal of Phonetics 24. 399-421.

Tucker, A.N. 1975. Voice quality in African languages. In Sayyid Hamid Hurreiz \& Herman Bell (eds.), Directions in Sudanese Linguistics and Folklore, 44-76. Carbondale, IL: Southern Illinois University.

Vaux, Bert. 1996. The status of ATR in feature geometry. Linguistic Inquiry 27. 175-182.

Ward, I. C. 1937. Phonetic phenomena in African languages. Archiv für die gesamte Phonetik 1.

Wayment, Adam. 2009. Assimilation as attraction: Computing distance, similarity, and locality in phonology. Baltimore, MD: John Hopkins University Ph.D. dissertation. http://roa.rutgers.edu/files/1071-0410/1071-WAYMENT-0-0.PDF.

Werle, Johannes-Martin \& Dagou Justin Gbalehi. 1976. Phonologie \& morphonologie du bété de la région de Guiberoua. Abidjan: Institut de Linguistique Appliquée \& Société Internationale de Linguistique.

Wescott, Roger W. 1962. A Bini grammar (Part 1: phonology). East Lansing, MI: Michigan State University African Language and Area Center.

Williamson, Kay. 1983. Vowel merger in harmony languages. Journal of the Linguistic Association of Nigeria 2. 61-82.

Yago, Zakaria. 1984. Le nuni. Abidjan, Côte d'Ivoire: Université Nationale de Cote D'Ivoire $\mathrm{Ph}$.D. dissertation.

Zsiga, E.C. 1997. Features, gestures, and Igbo Vowels: An approach to the phonology-phonetics interface. Language 73. 227-274.

Roderi Casali

roderic.casali@twu.ca
Submitted: 16 Dec 14

Accepted: 31 May 15

Revisions received: 15 Sept 15 